\title{
MASTE,
}
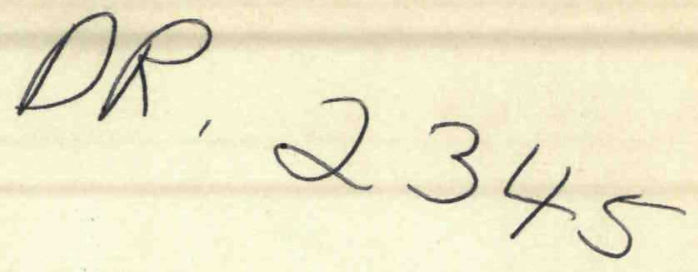

\section{In-Pile Steam Oxidation of Model HTGR Fuel Elements}

\author{
S. H. Freid \\ H. J. de Nordwall \\ A. P. Malinauskas
}




\section{Printed in the United States of America. Available from National Technical Information Service}

U.S. Department of Commerce 5285 Port Royal Road, Springfield, Virginia 22161

Price: Printed Copy $\$ 5.25$; Microfiche $\$ 3.00$

This report was prepared as an account of work sponsored by an agency of the United States Government. Neither the United States Government nor any agency thereof, nor any of their employees, contractors, subcontractors, or their employees, makes any warranty, express or implied, nor assumes any legal liability or responsibility for any third party's use or the results of such use of any information, apparatus, product or process disclosed in this report, nor represents that its use by such third party would not-infringe privately owned rights. 


\section{DISCLAIMER}

This report was prepared as an account of work sponsored by an agency of the United States Government. Neither the United States Government nor any agency Thereof, nor any of their employees, makes any warranty, express or implied, or assumes any legal liability or responsibility for the accuracy, completeness, or usefulness of any information, apparatus, product, or process disclosed, or represents that its use would not infringe privately owned rights. Reference herein to any specific commercial product, process, or service by trade name, trademark, manufacturer, or otherwise does not necessarily constitute or imply its endorsement, recommendation, or favoring by the United States Government or any agency thereof. The views and opinions of authors expressed herein do not necessarily state or reflect those of the United States Government or any agency thereof. 


\section{DISCLAIMER}

Portions of this document may be illegible in electronic image products. Images are produced from the best available original document. 


\title{
ORNL/TM-6399
}

Dist. Category UC-77

Contract No. W-7405-eng-26

CHEMICAL TECHNOLOGY DIVISION

IN-PILE STEAM OXIDATION OF MODEL HTGR FUEL ELEMENTS

S. H. Freid*

H. J. de Nordwall**

A. P. Malinauskas

\begin{abstract}
* Present affiliation: Bechtel Corporation, Norwalk, California.
**Present affiliation: Commission of the European Communities, Brussels, Be1gium.
\end{abstract}

NOTICE: This document contains information of a preliminary nature. It is subject to revision or correction and therefore does not represent a final report.

\section{Date Published: March 1979}

OAK RIDGE NATIONAL LABORATORY

Oak Ridge, Tennessee 37830 operated by

UNION CARBIDE CORPORATION

for the

DEPARTMENT OF ENERGY
This report was preTICE -

This report was prepared as an account of work sponsored by the United States Government. Neither the Fneray States nor the United States Department of Energy, nor any of their employees, nor any of their contractors, subcontractors, or their employees, makes any warranty, express or implied, or assumes any legal liability or responsibility for the accuracy, completeness or usefulness of any information, apparatus, product or process disclosed, or represents that its use would not infringe privately owned rights. 


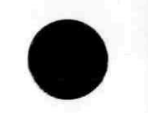

$\checkmark$

!

0 


\section{CONTENTS}

$\underline{\text { Page }}$

ABSTRACT . . . . . . . . . . . . . . . . . . . . . . . . 1

1. INTRODUCTION . . . . . . . . . . . . . . . . . . . . . . . 1

2. EXPERIMENTAL . . . . . . . . . . . . . . . . . . . 3

2.1 The In-Pile Reaction Furnace and Ancillary

Equipment . . . . . . . . . . . . . . . . . . . . . 3

2.2 The Model HTGR Fuel Elements . . . . . . . . . . 6

2.3 Analytical Instrumentation . . . . . . . . . . 13

2.4 Experimental Procedures . . . . . . . . . . . . . . . 15

3. RESULTS . . . . . . . . . . . . . . . . . . . . . . 18

3.1 Determination of Temperature Distributions . . . . . 18

3.2 Gaseous Fission Product Release Measurements . . . . 20

3.3 Solid Fission Product Distributions . . . . . . . . . 32

3.4 Fuel Particle Behavior... . . . . . . . . . . . . . 34

3.5 Fuel Element Oxidation . . . . . . . . . . . . . 41

4. CONCLUDING REMARKS . . . . . . . . . . . . . . . . 54

5. ACKNOWLEDGMENTS . . . . . . . . . . . . . . . . 56

6. REFERENCES. . . . . . . . . . . . . . . . . 57 
S. H. Freid*

H. J. de Nordwall**

A. P. Malinauskas

ABSTRACT

Mode1 HTGR fuel elements were exposed to various concentrations of steam while being irradiated under several sets of temperature conditions in the Oak Ridge Research Reactor. In one test, catalysis by iron impurities in the graphite casing of the fuel element caused a highly localized attack on the graphite by the steam; this resulted in the formation of deep pits in the casing. Furthermore, the iron impurities were sufficiently mobile to cause pitting attack on the pyrolytic carbon coatings of the fuel particles as we11.

The presence of steam induced a rapid increase in the release of gaseous fission products. However, the cessation of steam ingress in the primary system resulted in a pronounced, but correspondingly smaller, reduction in the level of gaseous release.

The incidence of fuel failure was greater than anticipated; however, even though the coatings of greater than $30 \%$ of the fue 1 had failed, the release of fission products beyond the fuel element itself was largely confined to iodine and the noble gases.

A novel mode of fuel failure was observed under the rather severe conditions of the tests; this involved the attack of the pyrolytic carbon coatings on intact particles by uncoated fragments of uranium fuel kernel material from failed particles.

\section{INTRODUCTION}

Modern high-temperature gas-cooled reactors (HTGRs) are characterized by massive graphite core and reflector regions which are supported by graphite structural members. The fuel for these reactors is in the form of pyrolytic carbon- and silicon carbide-coated fissile and fertile microspheres which are suspended in a partially graphitized carbon matrix. ${ }^{1}$ Use of these ceramic materials permits coolant outlet temperatures that are significantly higher (above $700^{\circ} \mathrm{C}$ ) than those of other types of nuclear * Present affiliation: Bechtel Corporation, Norwalk, California. **Present affiliation: Commission of European Communities, Brussels, Belgium. 
reactors; however, at these temperatures, the graphite can be readily attacked by the oxidizing impurities in the inert helium coolant.

The oxidant of primary concern under both normal and accident modes of operation is steam; the sources of steam inleakage involve the steam generator, heat exchangers in the auxiliary (or emergency) core cooling system, and the water bearings of the primary circuit circulators. The magnitudes of possible steam ingress range from relatively small but continuous inleakages from defective steam generator tubes to sudden, massive ingresses such as when a heat exchanger tube ruptures, which would initiate emergency reactor shutdown measures.

Oxidation of the graphite by steam is described by the chemical reaction

$$
\mathrm{C}(\mathrm{s})+\mathrm{H}_{2} \mathrm{O}(\mathrm{g}) \rightarrow \mathrm{CO}(\mathrm{g})+\mathrm{H}_{2}(\mathrm{~g}) .
$$

Examination of this reaction underscores two areas of concern - viz., the effects of graphite material loss and the significance of the production of two gases which are readily oxidized. Furthermore, hydrogen production may be enhanced by a secondary reaction,

$$
\mathrm{CO}(\mathrm{g})+\mathrm{H}_{2} \mathrm{O}(\mathrm{g}) \rightarrow \mathrm{H}_{2}(\mathrm{~g})+\mathrm{CO}_{2}(\mathrm{~g}) .
$$

In addition, the $\mathrm{CO}$ can also disproportionate in cooler regions of the primary circuit in accordance with the reaction,

$$
2 \mathrm{CO}(\mathrm{g}) \rightarrow \mathrm{C}(\mathrm{s})+\mathrm{CO}_{2}(\mathrm{~g}) ;
$$

this reaction can lead to the deposition of carbon on the heat exchanger tubes, causing a loss in heat transfer efficiency and an eventual loss in strength due to carburization of the metal.

The graphite in the core region serves as: (1) a neutron moderator, (2) a high-temperature structural material, and (3) a sink for fission product species or a barrier to their transport. Thus, the loss of graphite in the core region by steam corrosion can have three possible consequences of a primary character: (1) a loss of neutron moderation, (2) a loss in the structural strength of critical members, and (3) an enhanced release of fission products into the primary circuit coolant system. The graphite casing in which the fuel microspheres are contained, and the partially graphitized matrix in which the microspheres are suspended, also serve to retard failure of the pyrolytic carbon coatings 


$$
-3-
$$

due to corrosion by steam. This facet and, to a lesser extent, the effect of steam attack on the ability of the graphite to retard fission product migration form the topics of primary interest in this report. The loss of graphite by the steam oxidation of a model HTGR fuel element in-pile could not be quantitatively described using the reaction rate data determined out-of-pile because of the nature of the graphite materials employed.

Four in-pile experiments were conducted. Briefly, the experimental procedure was as follows: a small model HTGR fuel element consisting of a fuel rod in a cylindrical graphite casing was irradiated in a moisture-free atmosphere to generate fission products. It was then exposed to steam under various conditions. During steam exposure, temperature, reactant and reaction product concentrations, and gaseous fission product release rates were monitored. Moreover, an attempt was made to differentiate between oxidation of the graphite casing and oxidation of the matrix material in which the fuel microspheres were suspended by labelling the latter with ${ }^{14} \mathrm{C}$.

Following withdrawal of the fuel body from the reactor, a detailed postirradiation examination of the model fuel elements was conducted; the states of the fuel and the graphite were noted, integral carbon removal was measured, and fission product distributions were determined.

\section{EXPERIMENTAL}

\section{I The In-Pile Reaction Furnace and Ancillary Equipment}

A11 of the experiments were performed in the Oak Ridge Research Reactor (ORR), which is a 30-MW(th) water-moderated reactor using a square array of aluminum-clad (U,A1) alloy fuel elements. The experiment was assigned the F-9 lattice position for the installation of the permanent (i.e., used for all experiments) part of this facility. A second section, fabricated separately for each experiment, was then loaded into the permanent section. These sections are shown in Fig. 1 . The permanent section consisted of a lattice insert (H), foot valve (D), entry tube ( $G$ ), coupling box (A), and hollow hydraulic cylinder (B). The foot valve at the bottom of the lattice insert permitted loading and 


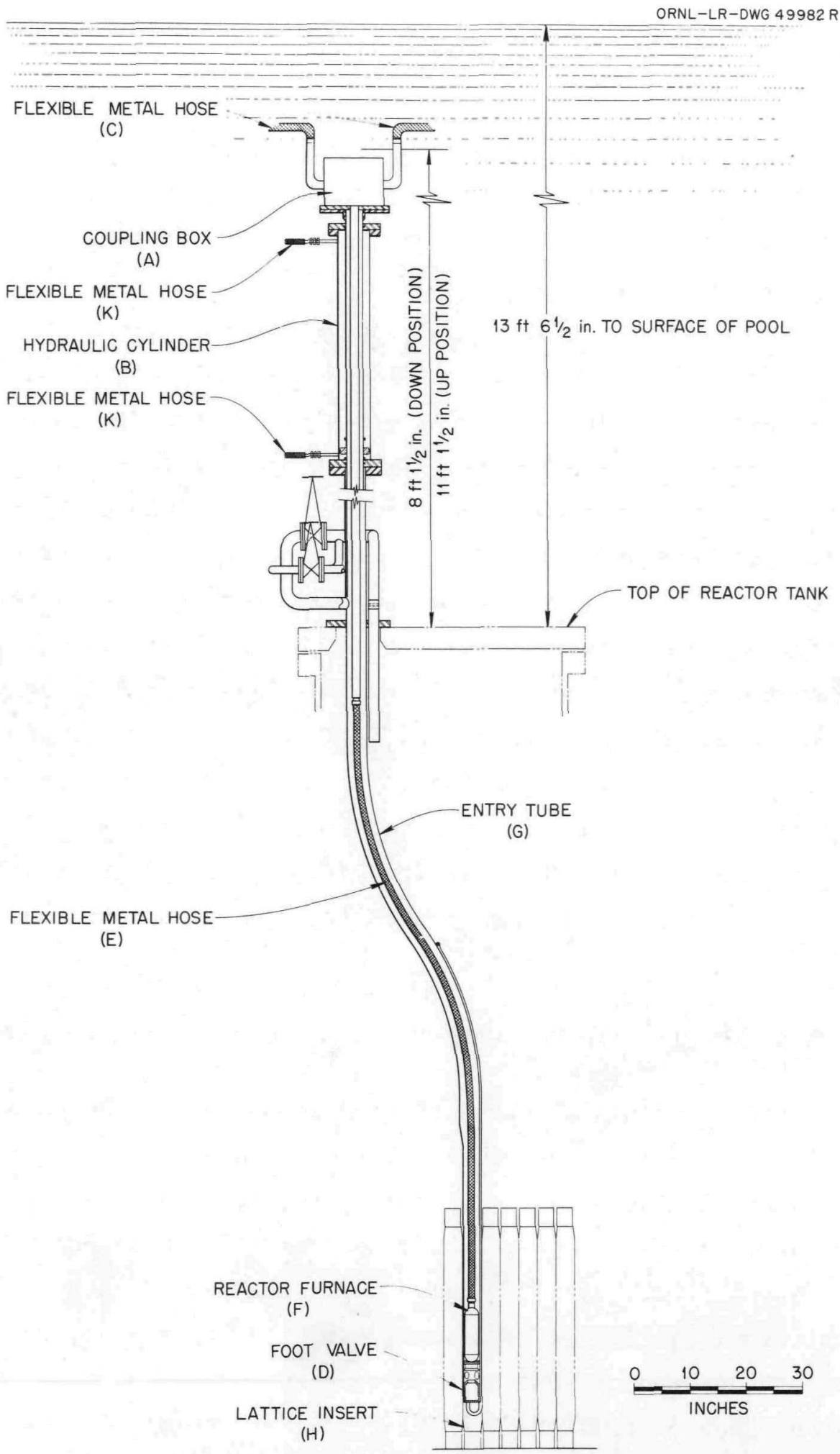

Fig. 1. In-reactor assembly of the experimental apparatus. 
removal of the renewable section while the reactor was at full power. The hollow hydraulic piston was designed so that the reactor furnace $(F)$, which contained the model fuel element, could be positioned at any point between the reactor centerline and approximately 20 inches above the top of the core, where the neutron flux was essentially zero.

The renewable section of the experimental assembly consisted of a long flexible hose that contained the inlet and exit gas lines and thermocouple extension wires leading to the reaction furnace. The design of the reaction furnace was aided by a computer-optimized heat transfer analysis ${ }^{2}$ and was based on several criteria. The first of these criteria was that the geometry of the graphite-steam interface be uncomplicated. Secondly, it was desirable to attain temperature differences between the fuel centerline and outer graphite casing surface that would be representative of real fuel elements at various positions in an HTGR core. Thirdly, a constant temperature difference between the fuel center and the graphite outer surface had to be maintained, within reasonable limits, while varying the graphite outer surface temperature.

The first objective was achieved by designing the reaction chamber so that steam could pass over only the outer surface of the fuel element. The ends were carefully masked with alumina insulators. These insulators also served to minimize axial heat transfer and to maintain a constant temperature along the fuel element.

The temperature differences and surface temperatures attained by the fuel element are dependent on the fission power and the heat transfer coefficients of all materials, from the fuel centerline to the experiment-reactor coolant interface. We decided to maintain a constant fuel element loading (for ease of fabrication) and to change the fission power by varying the neutron flux available at the fuel so that tests could be conducted over a relatively large range of surface temperatures $\left(700\right.$ to $1000^{\circ} \mathrm{C}$ ) and centerline-to-surface temperature differences (100$\left.250^{\circ} \mathrm{C}\right)$. As a result, the temperature difference attainable within the fuel element is a function of the flux and the furnace position. The surface temperatures that could be achieved were then defined by varying the gap thicknesses and gas compositions in those gaps that surrounded the reaction chamber. Gas composition could also be varied during the irradiation. 
The resultant design is shown in Figs. 2-4. There are three separate and distinct gas-filled segments surrounding the fuel compact. The first is the primary gas circuit that contains either pure helium or a helium-steam gas mixture. The second gas stream consists of a helium-argon mixture whose composition is varied to adjust the surface temperature of the sample once the desired centerline-to-surface temperature difference has been attained. The third gas annulus contains static helium and is part of the secondary containment system. By suitable sizing of the gaps through which the helium-argon gas mixtures flowed and by proper selection of materials used in the construction of the reaction chamber, it was possible to span a range of desired centerline and surface temperatures in the different experiments which were performed. The calculated thermal characteristics of the four configurations employed in this series of tests are presented graphically in Figs. 5 and 6 .

\subsection{The Model HTGR Fuel Elements}

Components of the model HTGR fuel elements that were used in these studies are depicted in Fig. 7. An individual fuel element consisted of a fuel pellet which contained pyrolytic carbon-coated $\mathrm{UC}_{2}$ and $\mathrm{ThO}_{2}$ microspheres, nominally 372- and 680- $\mu$ m diameters, respectively, which were embedded in a carbon matrix and enclosed by a graphite casing. The casing was machined from Great Lakes Carbon Company H-327 graphite, which is currently being used in fuel elements in the Fort St. Vrain

HTGR. ${ }^{3}$ As shown in Fig. 7, the casing was designed with three thermocouple wells on the outer surface and an end cap which was glued in place with carbon paste after the fuel pellet was inserted into the casing.

The fuel pellet was formed by heat treating a mold containing a formulation consisting of carbon black, V-15 pitch, and the fuel microspheres. Through error, the resultant mold was carbonized at a temperature of on $1 \mathrm{y} 1000^{\circ} \mathrm{C}$ instead of the intended 1500 to $1600^{\circ} \mathrm{C}$ heat treatment. As a result, weight losses and $\mathrm{CO}$ and $\mathrm{CO}_{2}$ production observed during experimentation could not be unequivocally ascribed to result from steam-graphite reaction in the usual sense of the terminology. 
ORNL DWG 69-4641

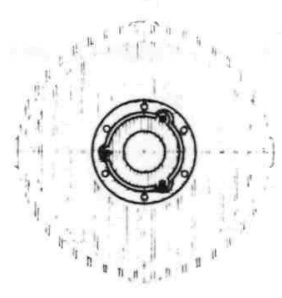

SECTION "A-A"

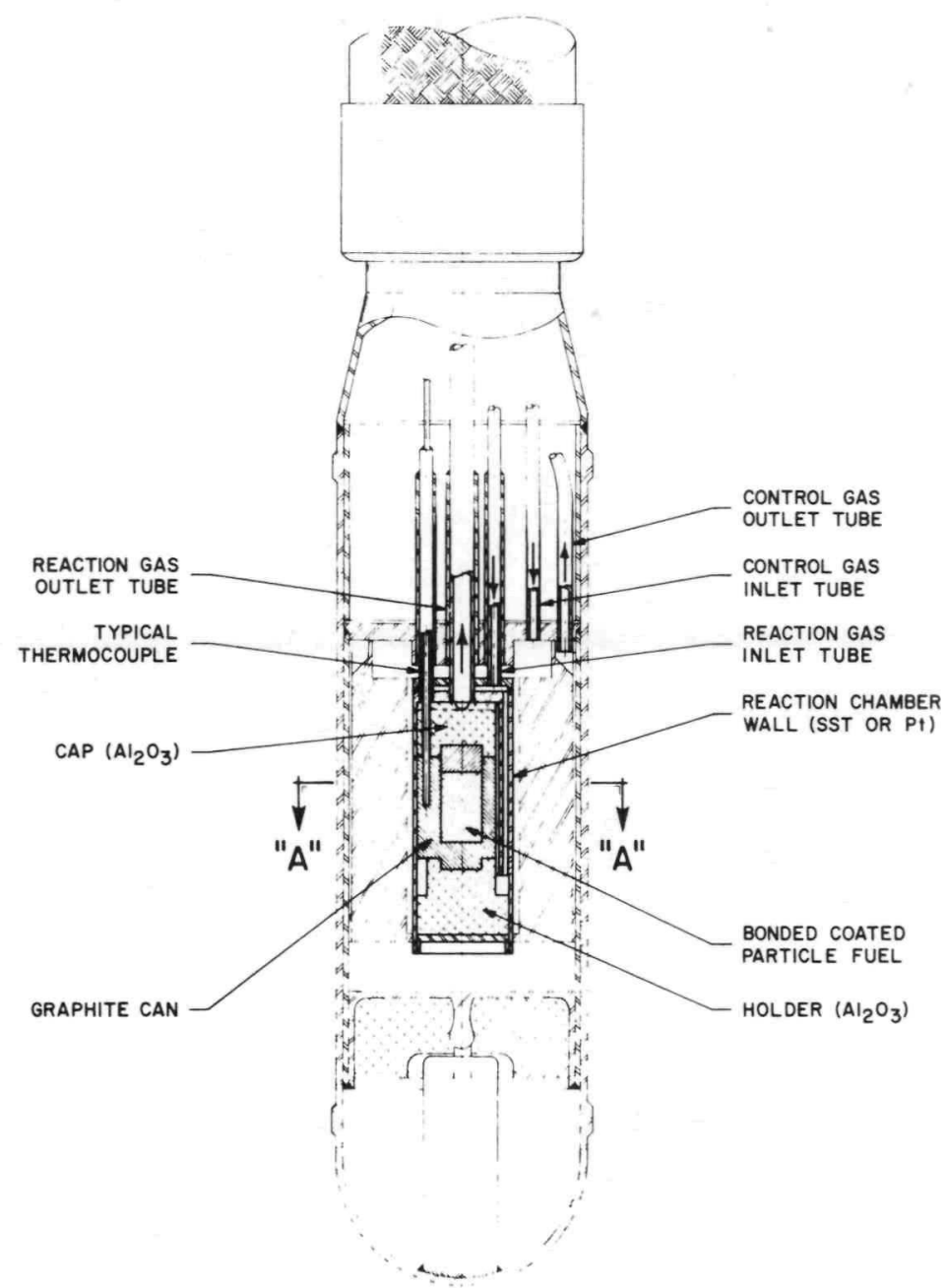

Fig. 2. Sketch of the in-pile capsule for steam-graphite reaction studies. 


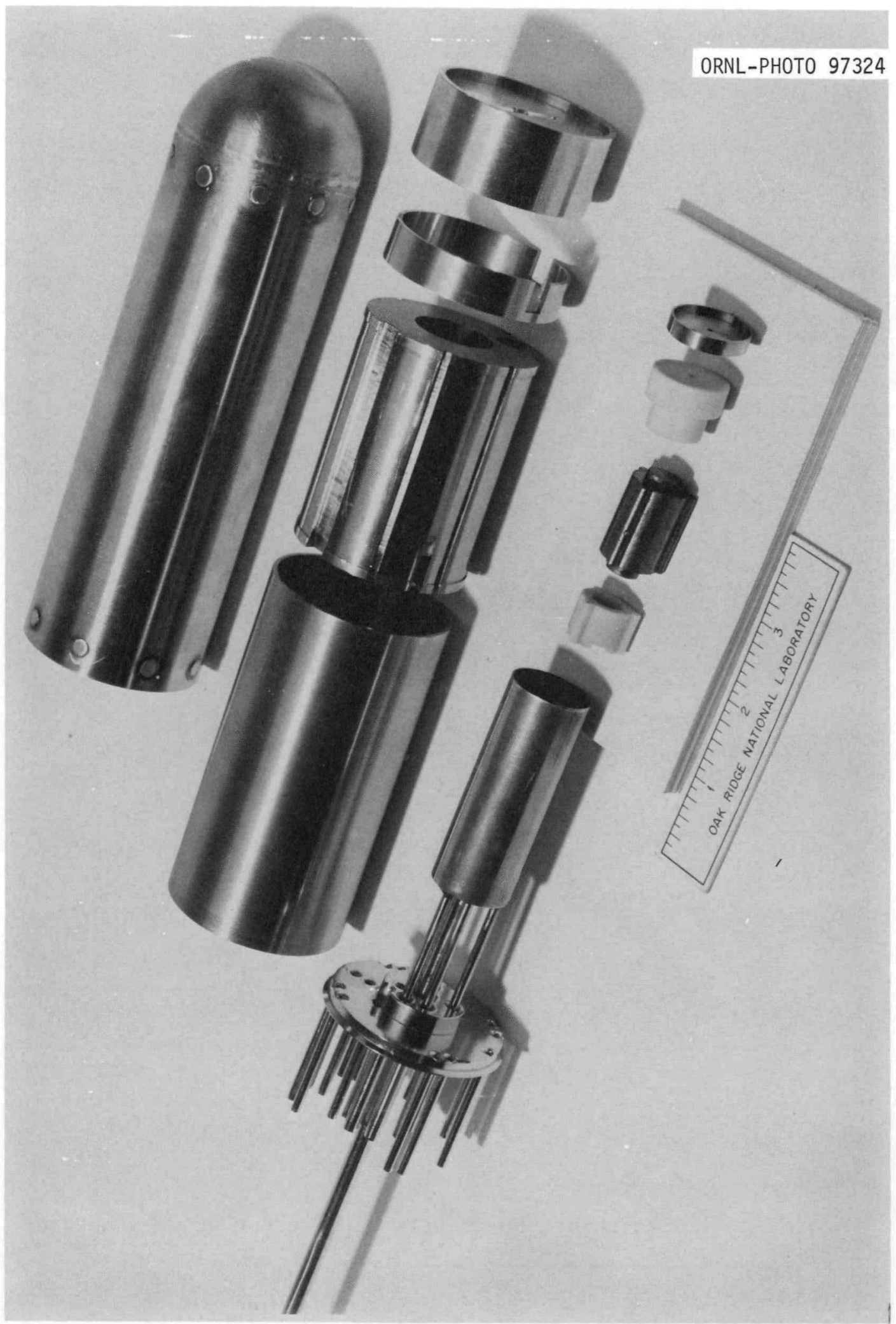

Fig. 3. Photograph of the in-pile capsule components. 


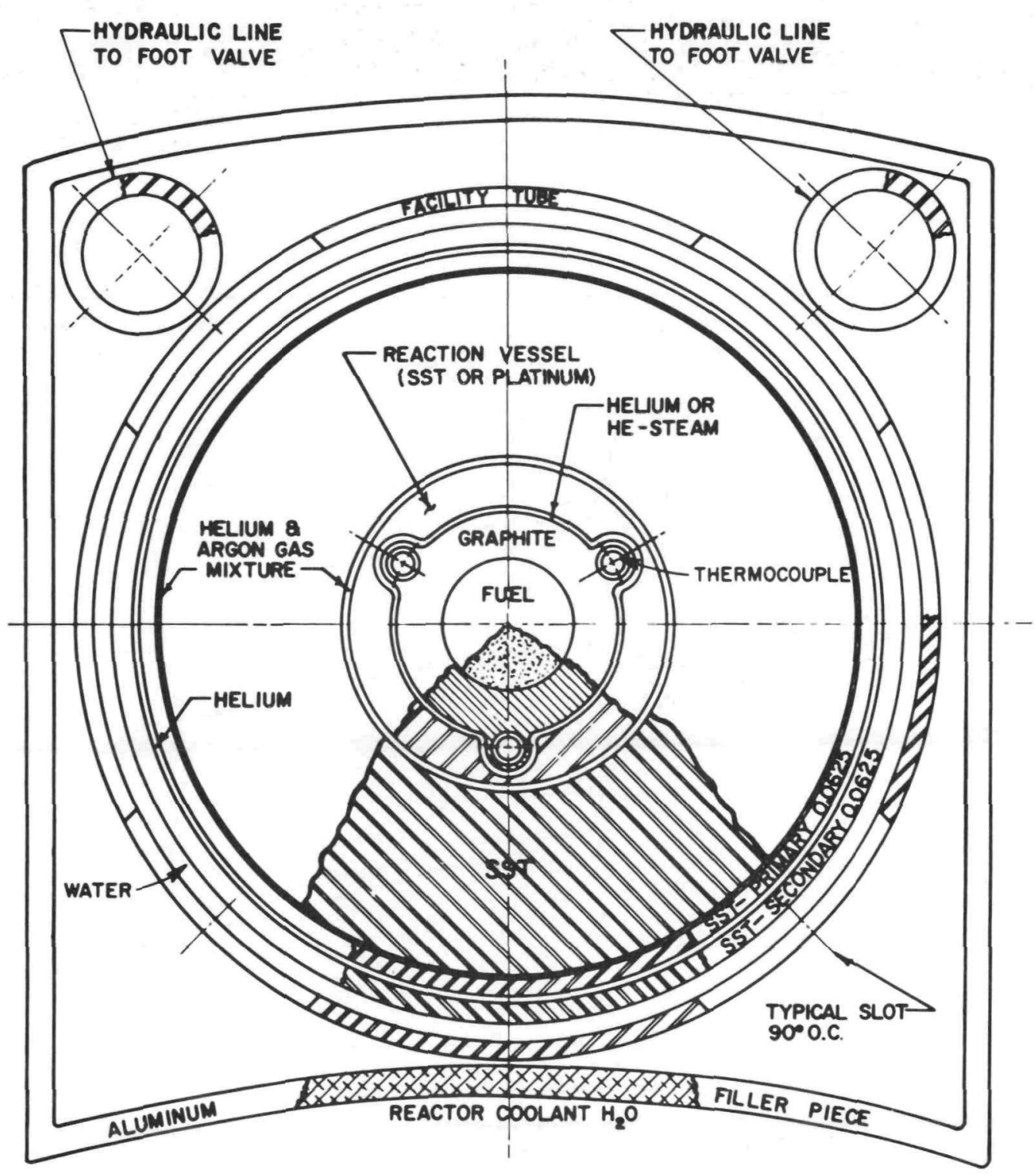

Fig. 4. Cross section of the in-pile assembly used in studies of the effects of steam ingress on a model HTGR fuel element. 


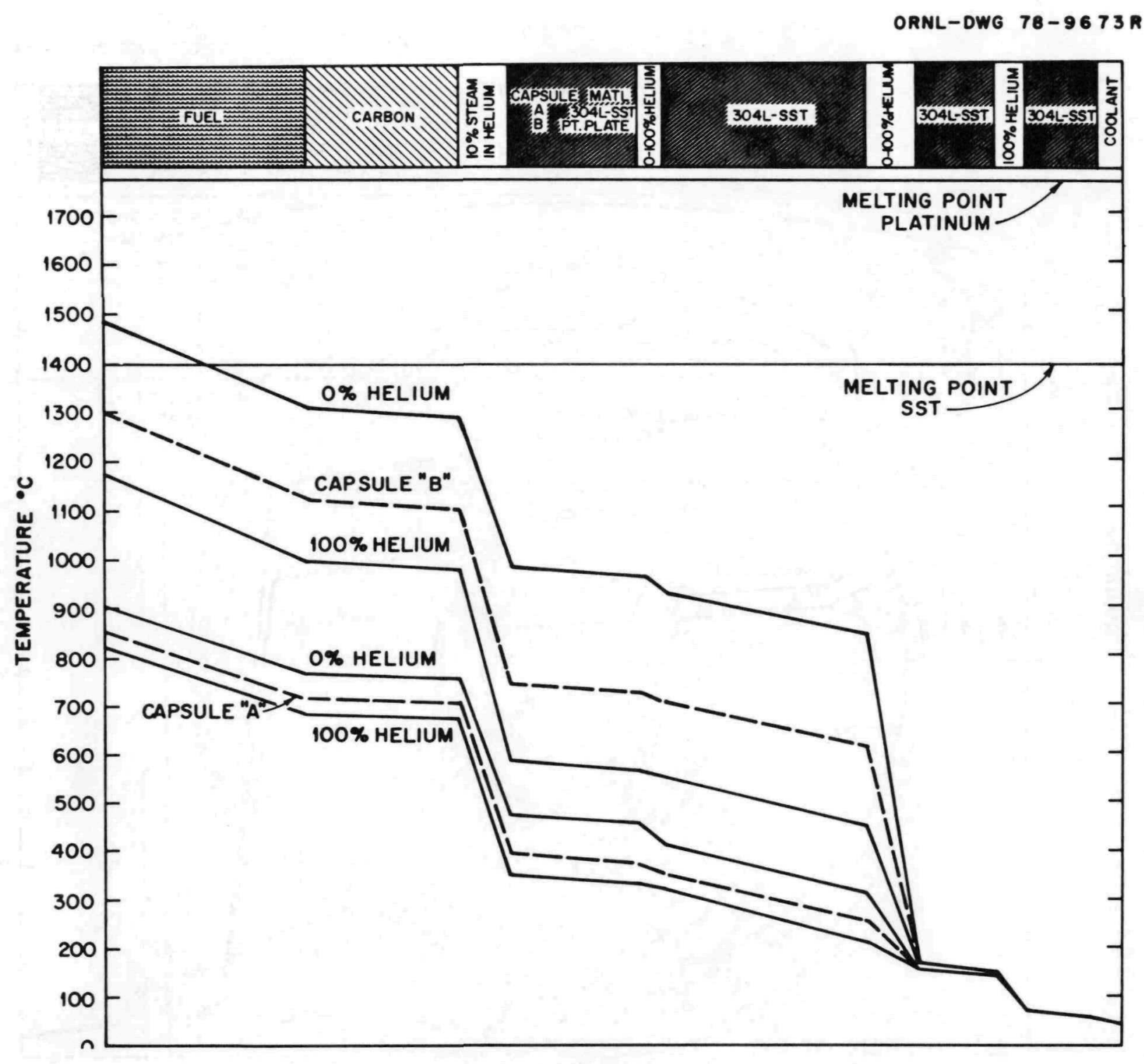

Fig. 5. Radial temperature profiles at target capsule locations in the F-9 position of the ORR as a function of percent helium (Capsules A and B). 


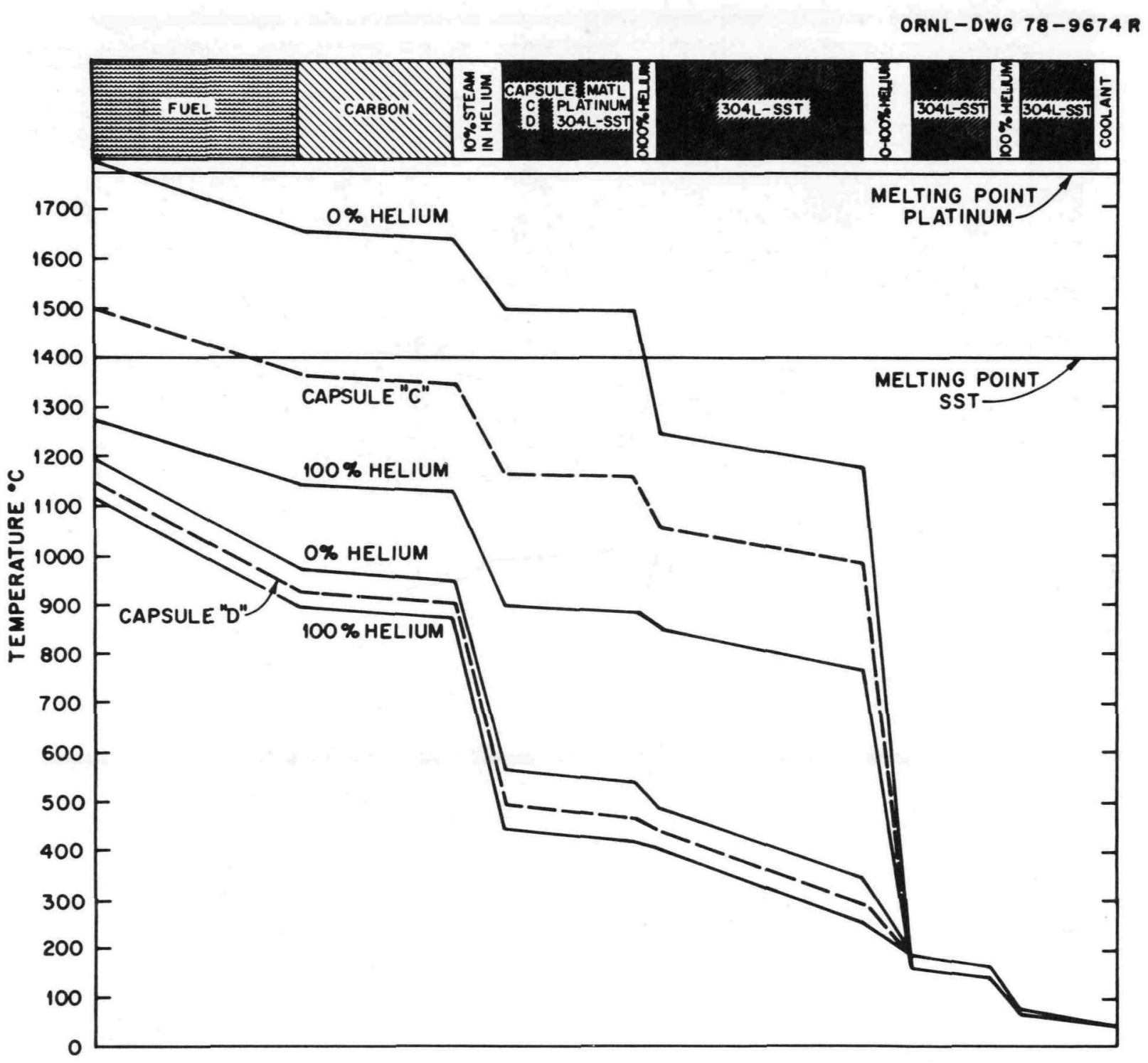

Fig. 6. Radial temperature profiles at target capsule locations in the F-9 position of the ORR as a function of percent helium (Capsules $\mathrm{C}$ and D). 


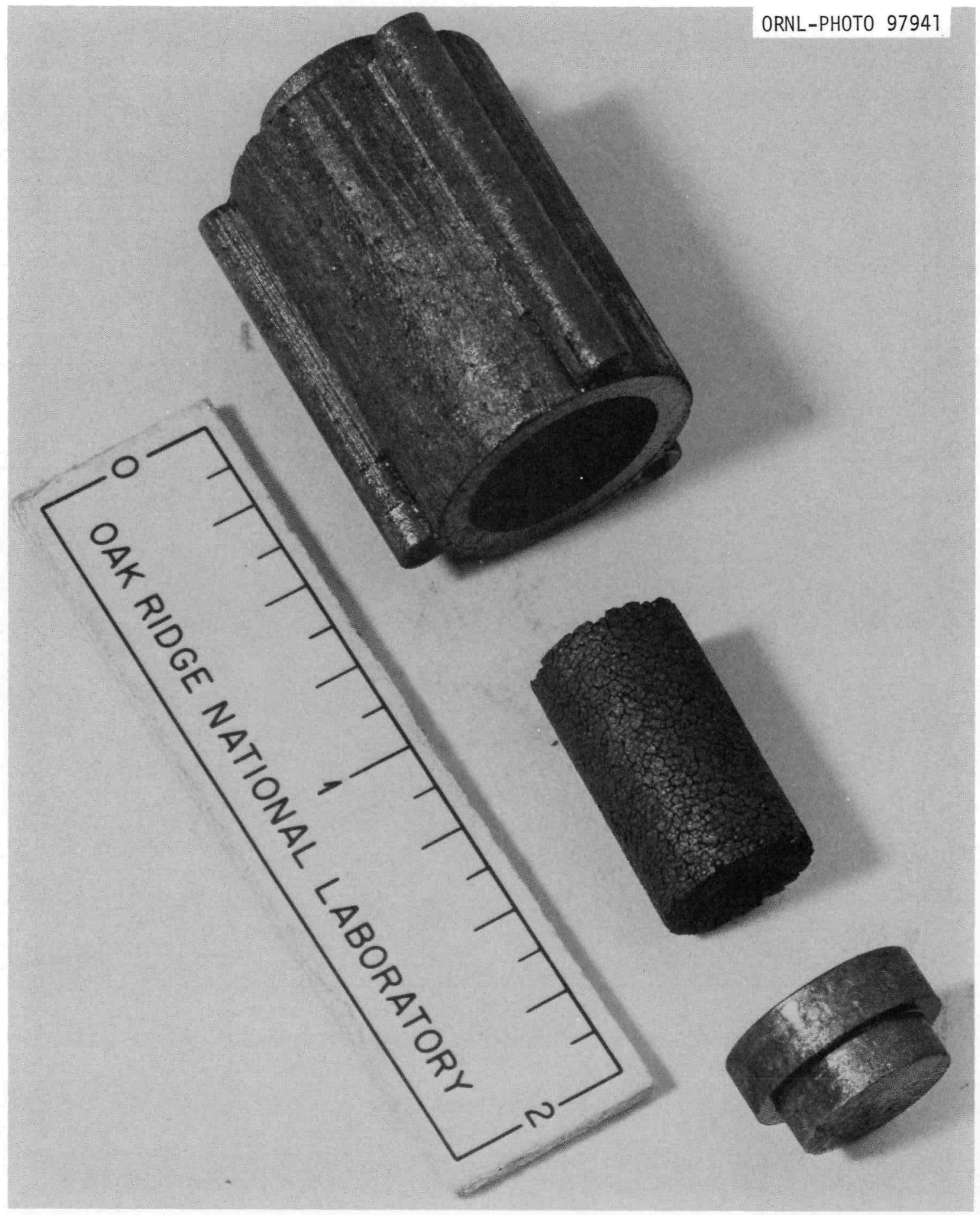

Fig. 7. Components of the model HTGR fuel element. 
The carbon black that was employed was supplied by Malinkrodt Chemical Company. It was formed by the thermal decomposition of $\mathrm{C}_{2} \mathrm{H}_{2}$ and was spiked with ${ }^{14} \mathrm{C}$ to permit differentiation between steam attack of the graphite casing and the carbon matrix of the fuel pellet.

The final fuel pellet, in the form of a 0.70-in.-1ong cylinder with a 0.42-in. diameter, contained $~ 60 \%$ fuel particles; the density of the matrix in which the particles were embedded was calculated to be about $0.7 \mathrm{~g} / \mathrm{cm}^{3}$.

\subsection{Analytical Instrumentation}

The primary gas circuit is shown schematically in Fig. 8. The helium or helium-steam gas stream flowed past the outside surface of the fuel piece and then entered a shielded cubicle that contained the analytical instrumentation. These instruments were arranged so that each element of the analytical system could be controlled individually. A master controller on the primary gas line maintained a constant system pressure. The analytical instrumentation consisted of the following:

1. A gamma-spectrometer was used to continuously monitor the state of the fuel by observing ${ }^{88} \mathrm{Kr}$ gas release at a constant primary gas flow.

2. A gas-sampling station obtained "grab" samples of the primary gas for detailed isotopic analysis using a Ge(Li) detector coupled to a small computer.

3. A process infrared analyzer was used for continuous measurement of CO content. This instrument was used to estimate the amount of carbon removal during each steam exposure; it also proved to be extremely valuable in detecting flow blockages during steam injection.

4. Changes in the chemical composition of the primary coolant during steam injection were detected by a monopole mass spectrometer.

5. A series of traps were used to assay the exiting primary gas for oxides of carbon. This sampling station consisted of two Ascarite* traps which were separated by a heated copper oxide

*Ascarite is a proprietary sodium hydrate asbestos absorbent. 


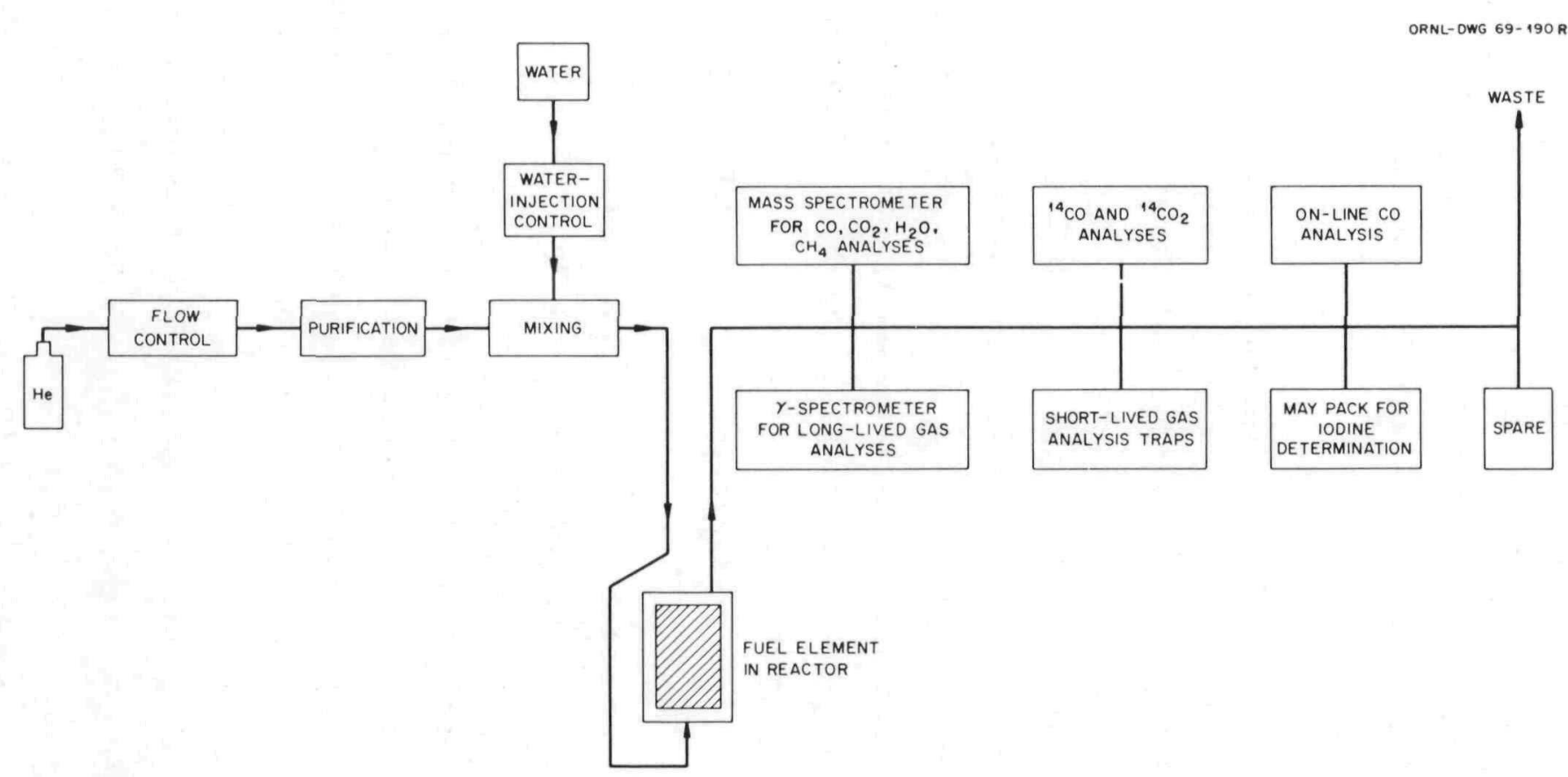

Fig. 8. Schematic representation of the primary gas circuit of the in-pile assembly. 
bed. The first trap removed $\mathrm{CO}_{2}$ from the primary gas sample stream. The stream was then passed through the copper oxide bed where the $\mathrm{CO}$ was oxidized to $\mathrm{CO}_{2}$ and subsequent1y collected in the second Ascarite trap. Both the ${ }^{14} \mathrm{C} /{ }^{12} \mathrm{C}$ ratios and total amounts of $\mathrm{CO}_{2}$ collected in the two traps were determined.

Water was removed from the primary gas prior to sampling and online $\mathrm{CO}$ analysis through the use of $\mathrm{H}_{2} \mathrm{SO}_{4}$ traps.

\subsection{Experimental Procedures}

The experimental procedures were developed primarily with an aim toward maximizing the amount of information that could be obtained from a test rather than mimicking a hypothetical accident sequence. The target operating temperatures of the four tests are summarized in Table 1 .

After the capsule was loaded into the reactor, it was brought to the desired irradiation temperature and the fuel was allowed to generate fission products. After a few days of operation, the steam was admitted into the primary system for a specified period of time and the appropriate experimental data were taken and recorded. Steam ingress was then terminated, and the system was allowed to return to a stable condition. The infrared analyzer generally indicated that there was no $\mathrm{CO}$ in the system between steam exposures. Noble gas release always increased during steam oxidation and then decreased, although not to its previous level, when the steam supply was shut off. After the system returned to a stabilized condition, either a second steam injection was conducted direct1y or the temperatures were adjusted and the system was allowed to stabilize prior to a second steam injection. This sequence was then followed until the test plan was completed or until it became necessary to discontinue further experimentation. The time-temperature sequences actually employed in the tests are summarized graphically in Figs. 9 and 10.

At the conclusion of the experiment, the in-pile section was removed from the reactor and disassembled for examination in a hot cell. Fuel burnup was less than $1 \%$ in Experiments $\mathrm{A}$ and $\mathrm{B}$, and about $1.5 \%$ in 


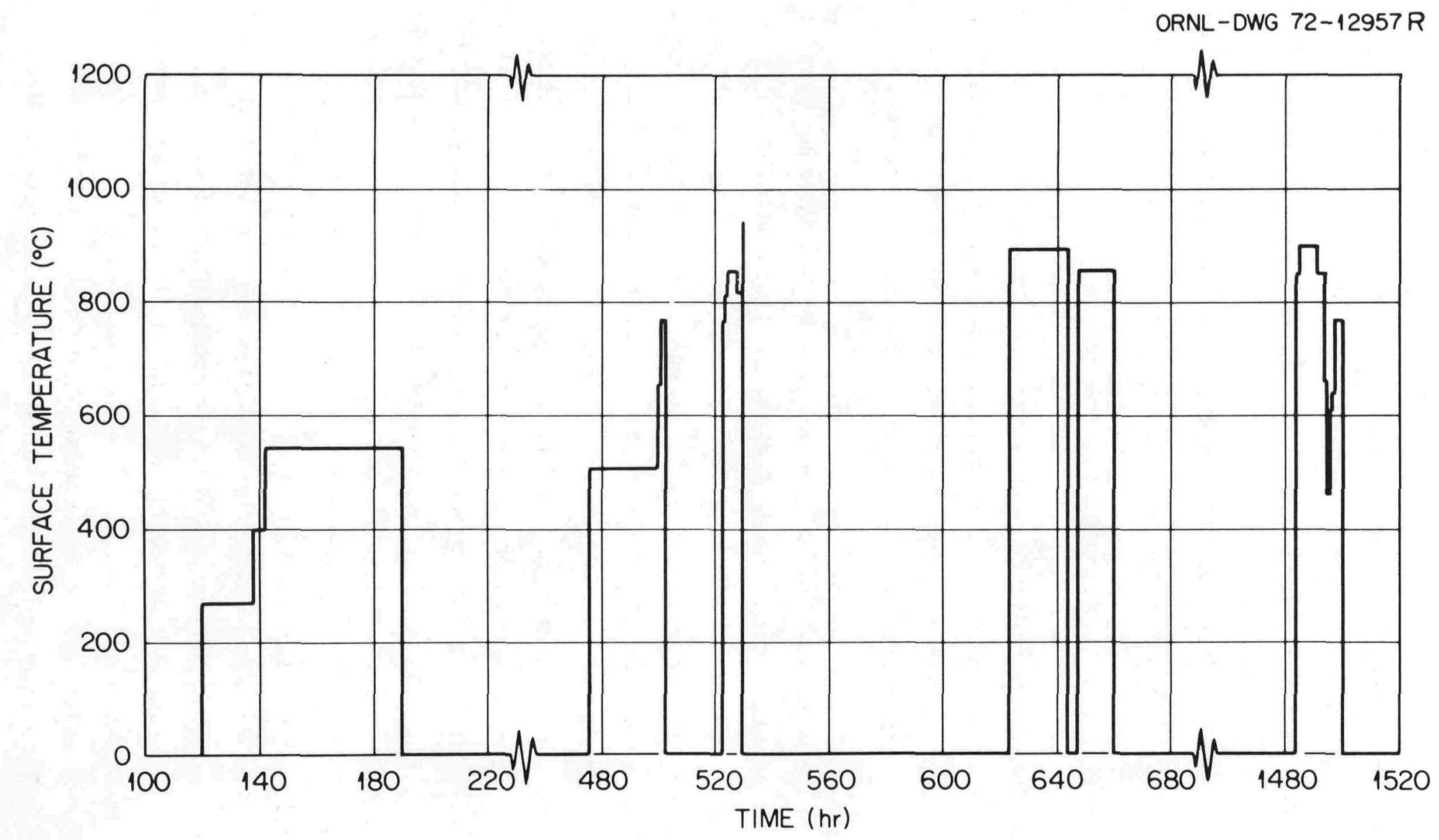

Fig. 9. Time-temperature history of the in-pile steam-graphite Experiment A. 


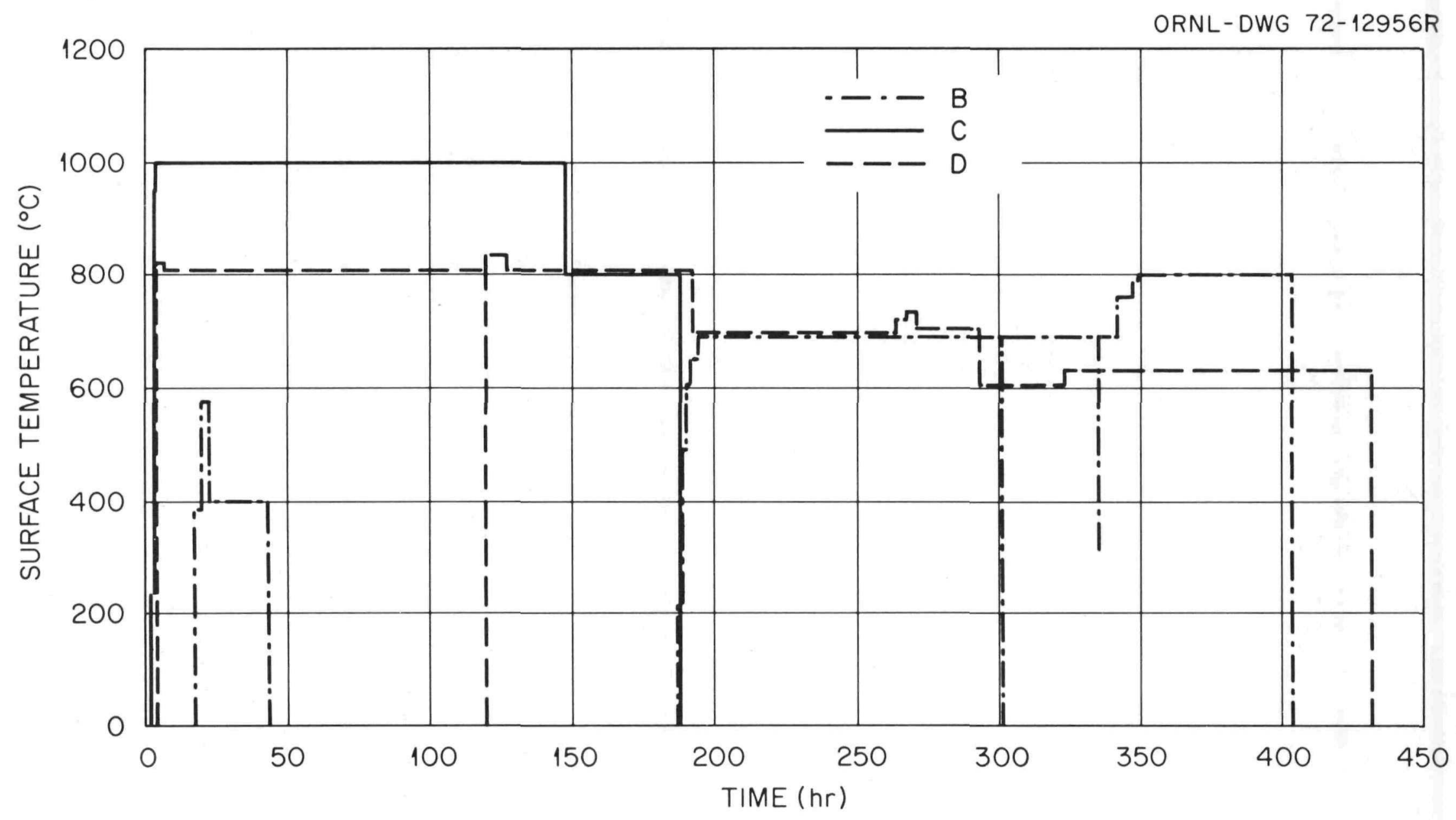

Fig. 10. Time-temperature histories of the in-pile steam-graphite Experiments $\mathrm{B}, \mathrm{C}$, and $\mathrm{D}$. 
Table 1. Design fuel element temperatures for the in-pile experiments

\begin{tabular}{crcc}
\hline \multirow{2}{*}{ Experiment } & \multicolumn{2}{c}{ Fuel element temperatures $\left(^{\circ} \mathrm{C}\right)$} \\
\cline { 2 - 4 } A & 850 & Surface & Difference \\
B & 1300 & 1100 & 150 \\
C & 1500 & 1350 & 200 \\
D & 1150 & 900 & 150 \\
\hline
\end{tabular}

Experiments C and D. Because the fuel loading was high compared to the amount of carbon in the model fuel element, significant fission product concentrations were produced in the tests. Moreover, the graphite casings were generally in excellent condition after experimentation, although much of the carbon matrix of the fuel pellet was usually removed and fuel coatings had been damaged.

\section{RESULTS}

\subsection{Determination of Temperature Distributions}

The analysis ${ }^{2}$ that was used to assist in the design of the capsules assumed a thermal conductivity characteristic of the fuel pellet of $0.012 \mathrm{cal} / \mathrm{cm}-\mathrm{sec}-{ }^{\circ} \mathrm{C}\left(3 \mathrm{Btu} / \mathrm{hr}-\mathrm{ft}-{ }^{\circ} \mathrm{F}\right)$. Thus, an objective of the first test (Experiment A) was to evaluate the accuracy of the assumed value. However, the formulation of the fuel pellet carbon matrix was changed after the first test, so the same objective was also included in the second test (Experiment B). As a result, in both experiments the model fuel element was additionally equipped with a platinum-sheathed thermocouple that extended into the center of the fuel rod. This thermocouple, along with those located in the thermocouple wells described previously, permitted measurements of the fuel centerline temperature as well as fuel body surface temperature.

The difference in temperature, $\Delta \mathrm{T}$, between the fuel centerline and the surface of the model fuel element was predicted to be described by the relation: 


$$
\Delta \mathrm{T}=\left[\left(2.58 \times 10^{-13} / \mathrm{K}_{\mathrm{G}}\right)+\left(2.93 \times 10^{-13} / \mathrm{K}_{\mathrm{F}}\right] \emptyset_{\mathrm{P}},\right.
$$

in which $\Delta \mathrm{T}$ is the temperature difference in degrees centigrade, $\mathrm{K}_{\mathrm{G}}$ and $\mathrm{K}_{\mathrm{F}}$ represent the thermal conductivities of the graphite casing and the fuel pellet, respectively, in cal/cm-sec $-{ }^{\circ} \mathrm{C}$, and $\phi_{\mathrm{P}}$ is the perturbed neutron flux, in neutrons $/ \mathrm{cm}^{2}-\mathrm{sec}$. The first term in Eq. (4) yields the temperature drop across the graphite casing, whereas the second term corresponds to the difference in temperature between fuel centerline and the fuel pellet-graphite casing interface.

Flux perturbation factors were obtained for each experimental configuration. Several flux maps were made during the course of the experiments, and these were averaged to yield an unperturbed flux versus capsule position curve.

The values employed for the thermal conductivity of the graphite casing were obtained from the equation:

$$
\mathrm{K}_{\mathrm{G}}=\left[80.35 /\left(\mathrm{T}_{\mathrm{S}}+273\right)\right]+0.0425,
$$

where $\mathrm{K}_{\mathrm{G}}$ is expressed in the units already indicated and $\mathrm{T}_{\mathrm{S}}$ denotes the surface temperature of the graphite in degrees centigrade. The numerical values indicated in Eq. (5) were derived from an analysis of data presented by Cobb, Engle, and Perry. ${ }^{3}$

The thermal conductivity values of the fuel pellet that were derived from Experiment $B$ of the test series could be described by the relationship

$$
\mathrm{K}_{\mathrm{F}}=\left(2.4 \times 10^{-5}\right) \mathrm{T}_{i}-6.6 \times 10^{-3},
$$

in which $\mathrm{T}_{\mathbf{i}}$ represents the temperature, in degrees centigrade, at the fuel pellet-graphite casing interface.

In each assembly, the fuel compact was specially fitted into its graphite casing, so it was assumed that no gap existed between the pellet and the casing. In addition, no allowance was made for changes in the thermal conductivity characteristics of the model fuel elements because of corrosion by steam. However, the results obtained in Experiment A indicated that oxidation decreased the average thermal conductivity of the fuel element by about a factor of 2 .

Temperatures derived from the thermal analysis summarized above for Experiments B, C, and D are presented in Table 2. 
Table 2. Calculated and observed temperatures for Experiments B, C, and D

\begin{tabular}{ccccc}
\hline Experiment & $\begin{array}{c}\text { Observed surface } \\
\text { temp. }\left({ }^{\circ} \mathrm{C}\right)\end{array}$ & $\begin{array}{c}\text { Calculated fuel- } \\
\text { graphite interface } \\
\text { temp. }\left({ }^{\circ} \mathrm{C}\right)\end{array}$ & $\begin{array}{c}\text { Centerline temp. } \\
\left({ }^{\circ} \mathrm{C}\right)\end{array}$ \\
\hline B & 768 & 732 & 1075 & 1060 \\
& 788 & 816 & 1245 & 1190 \\
& 808 & 848 & 1292 & 1240 \\
& 982 & 876 & 1359 & 1310 \\
C & 793 & 1040 & 1333 & - \\
& 820 & 847 & 1064 & - \\
& 730 & 891 & 1379 & - \\
\hline
\end{tabular}

\subsection{Gaseous Fission Product Release Measurements}

Radioactive gas species that entered the coolant stream were monitored continuously using a sodium iodide crystal gamma-ray spectrometer and intermittently using a gas bottle sampling system. Only the gamma-ray spectrometer was employed in the first two experiments. In both tests it was noted that the admission of steam to the model fuel elements resulted in a rapid and significant increase in the radioactivity of the effluent stream; however, curtailment of the steam supply always resulted in a pronounced, but a correspondingly smaller, decrease in the gaseous radioactivity level. The gas bottle sampling system was employed in addition to the spectrometer during the third test of the series, and several samples were obtained for high-resolution gamma-ray spectroscopy. Analysis of these samples indicated that the variations in radioactivity levels were the same for all of the nuclides detected. 
During Experiment D, a sufficient number of gas samples were taken so that the phenomenon could be observed in detail; the results for ${ }^{88} \mathrm{Kr}$ are summarized graphically in Fig. 11 in which the release rate-to-birth rate ratio, $R / B$, is presented as a function of time elapsed from insertion of the capsule into the reactor. The gas samples were ordinarily taken between steam exposures while the system was being allowed to stabilize, just prior to the admission of steam into system, within a half-hour interval after steam ingress, just prior to the curtailment of the steam supply, and within a halfhour interval following steam stoppage. The results obtained for all of the krypton and xenon nuclides observed before, during, and after the first, third, and fourth steam exposures of Experiment D are presented in Figs. 12 to 20. In these figures, the $R / B$ values for the various sampling times are plotted as a function of the nuclide decay constant, $\lambda$.

In general, variations in the values for each nuclide during constant operating conditions is small, and the $R / B$ values tend to cluster about a single line of the mathematical form:

$\ln (\mathrm{R} / \mathrm{B})=\mathrm{A}-(1 / 2) \ln \lambda$.

Carrol1, Perez, and Sisman $^{4}$ have demonstrated that this is the form to be expected if the release rate is characteristic of a diffusional process. However, we have been unable to account for the sudden increases in release rate with steam injection; these increases do not appear to be due primarily to steam corrosion-induced particle failure, since the initial rapid release of gaseous fission products is not sustained over the several hour period during which steam is present. In addition, we have not been able to satisfactorily account for the decrease in fission gas release upon cessation of steam ingress. The extent to which oxidation of the carbide fuel by steam and the consequent restructuring of the fuel are responsible for the phenomenon observed remains conjectural; tests with oxide fuel are required to further elucidate the nature of the phenomenon. 


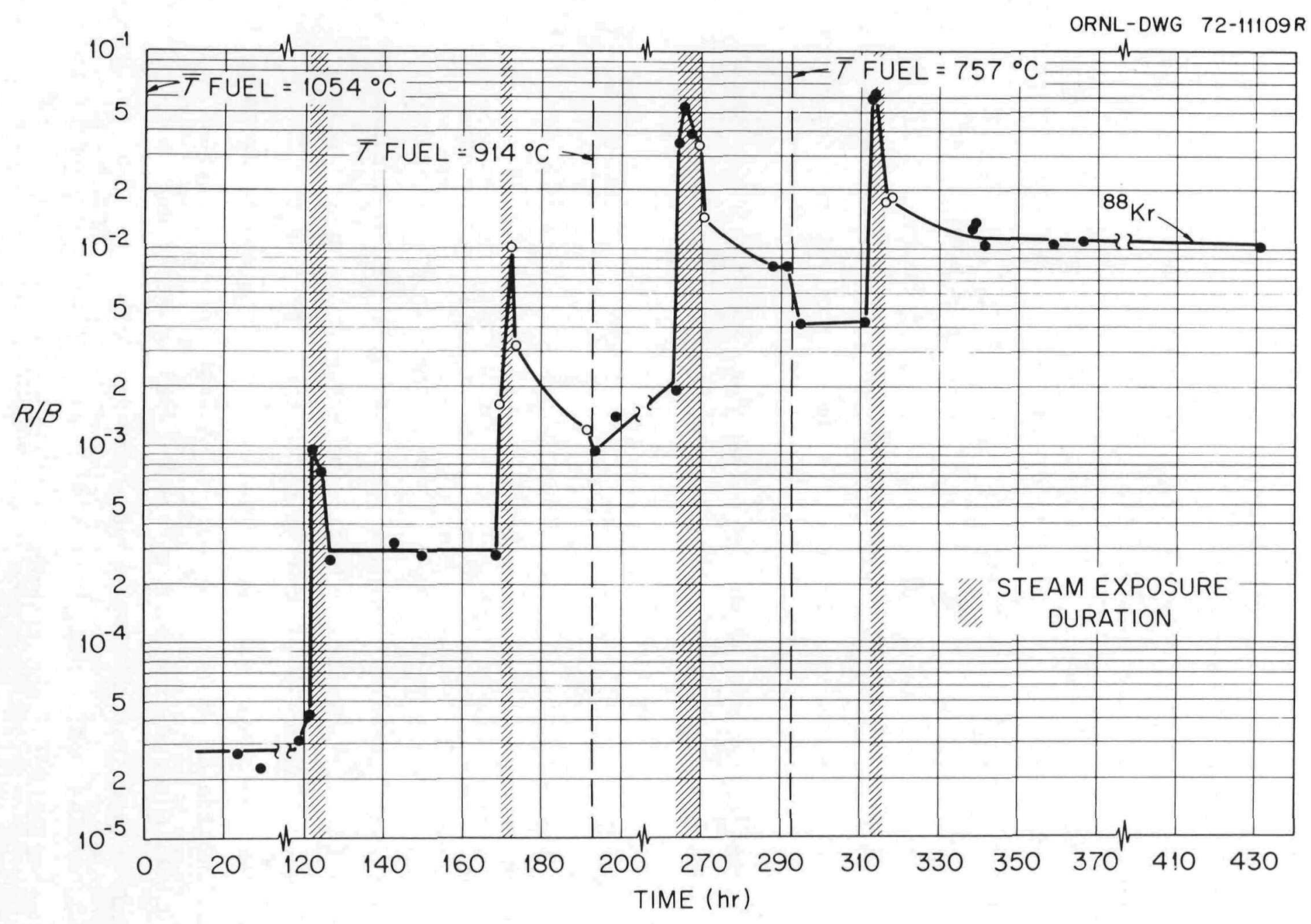

Fig. 11. Krypton-88 release rate-to-birth rate ratio during in-pile Experiment D. 


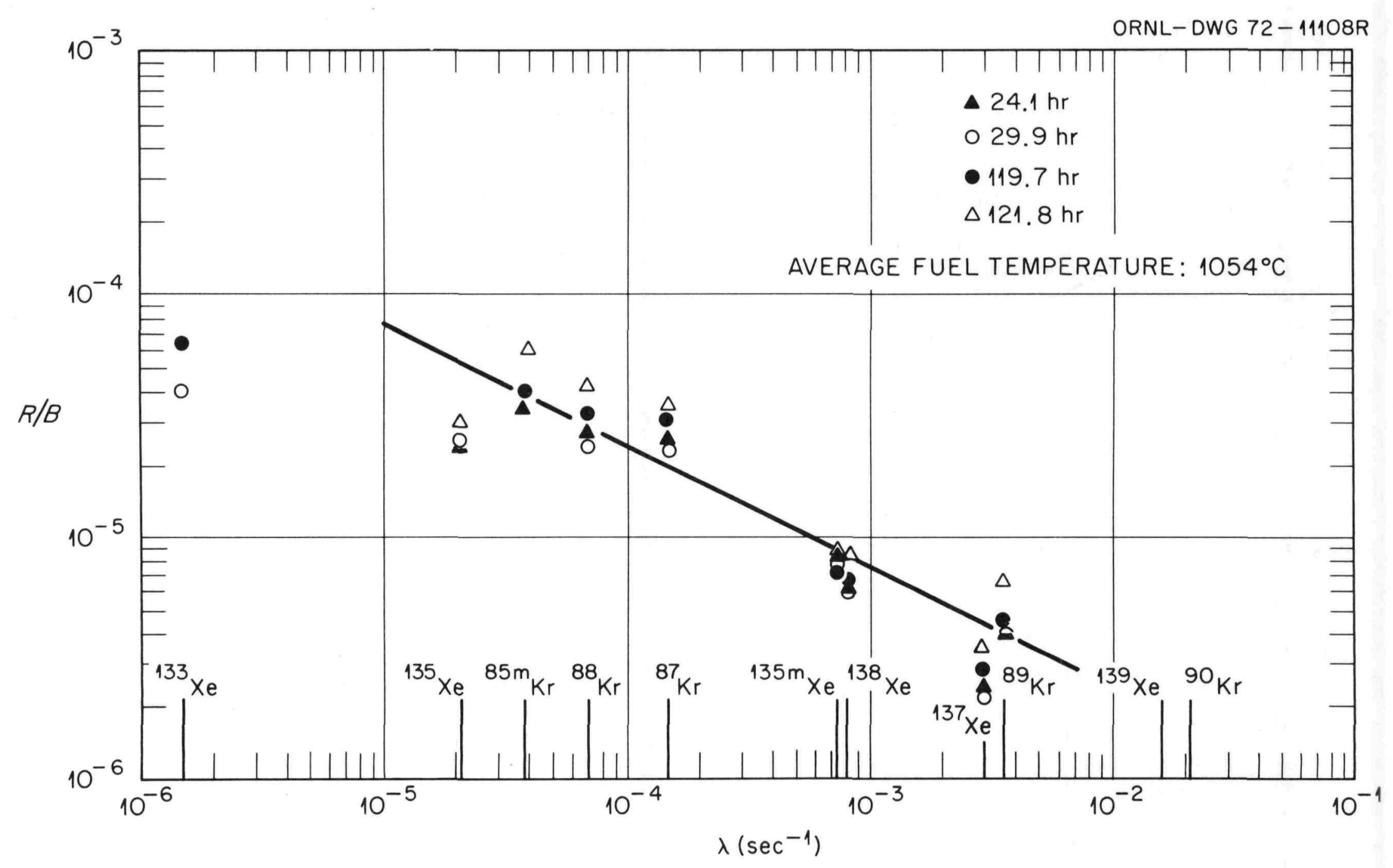

Fig. 12. Experiment D. R/B values prior to first steam injection. 


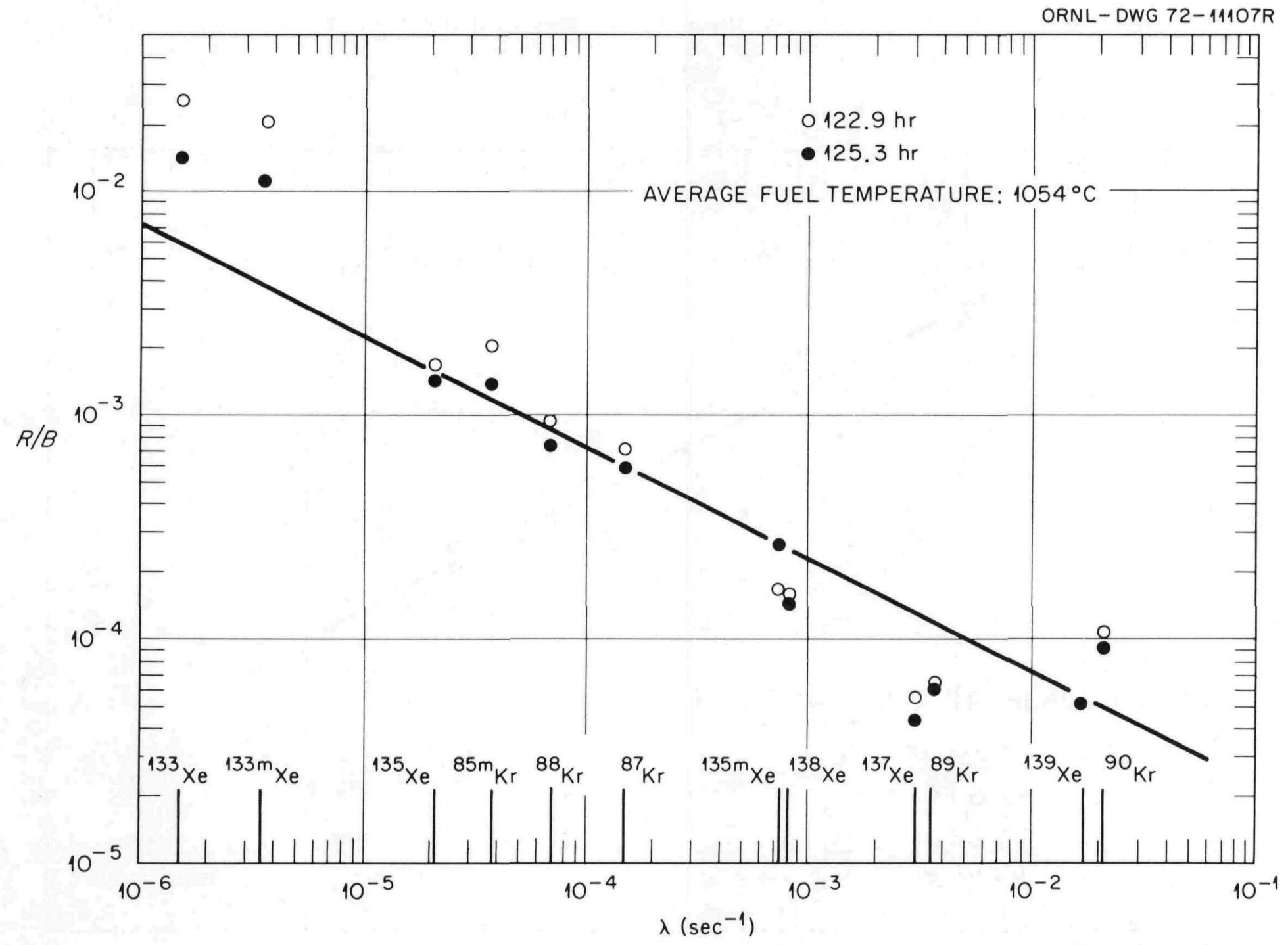

Fig. 13. Experiment D. R/B values during first steam injection. 


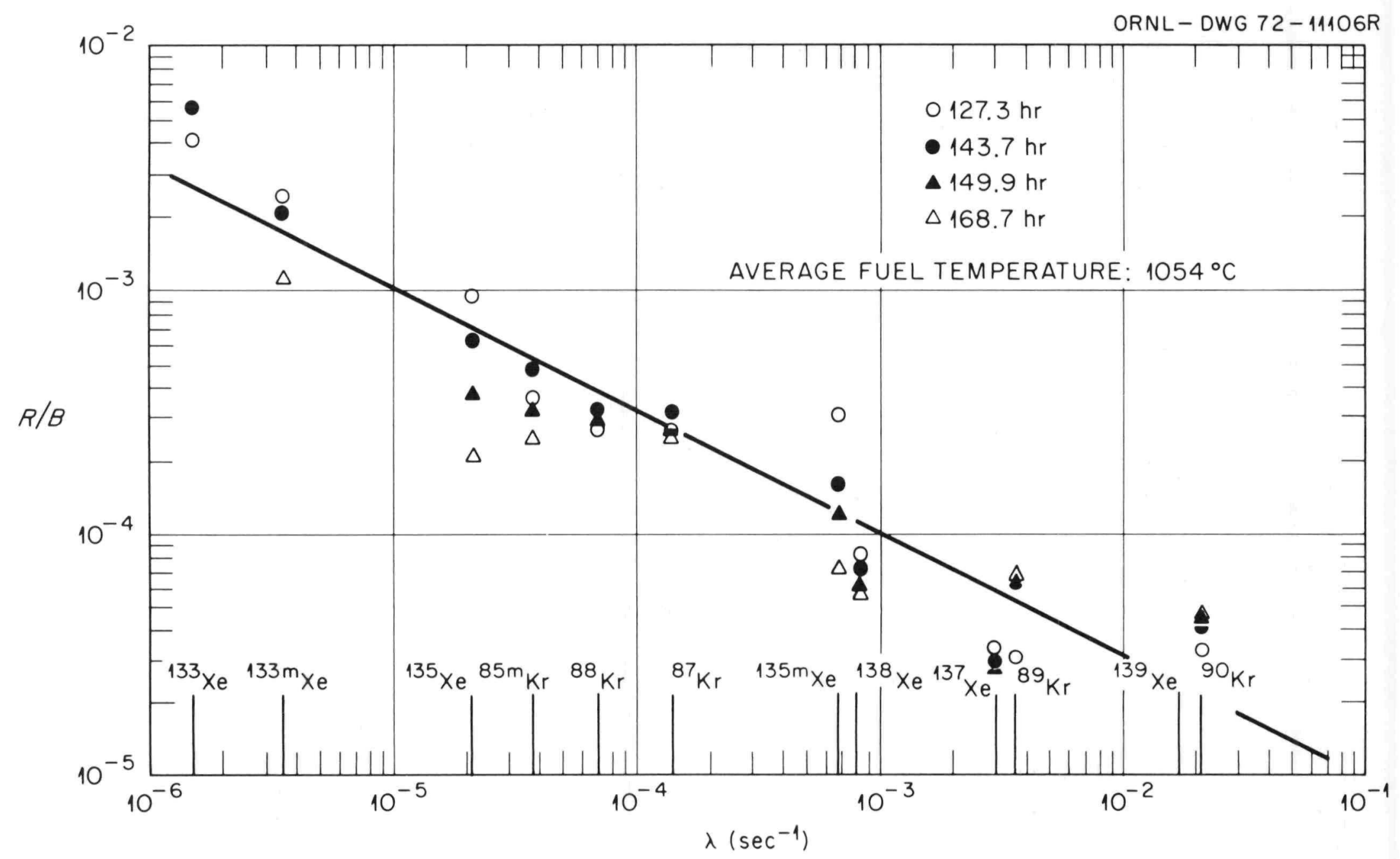

Fig. 14. Experiment D. R/B values after first steam injection. 


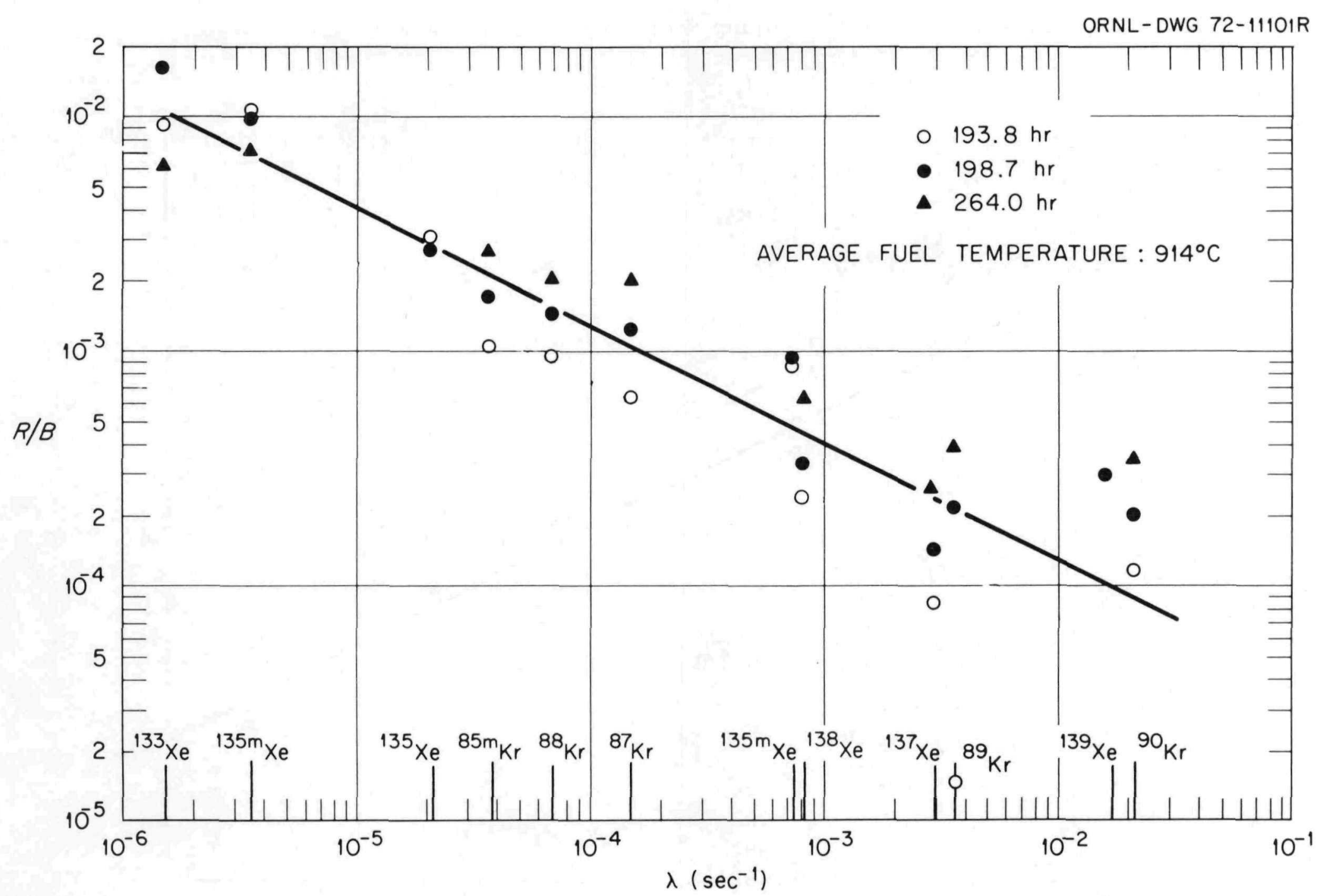

Fig. 15. Experiment D. R/B values prior to third steam injection. 


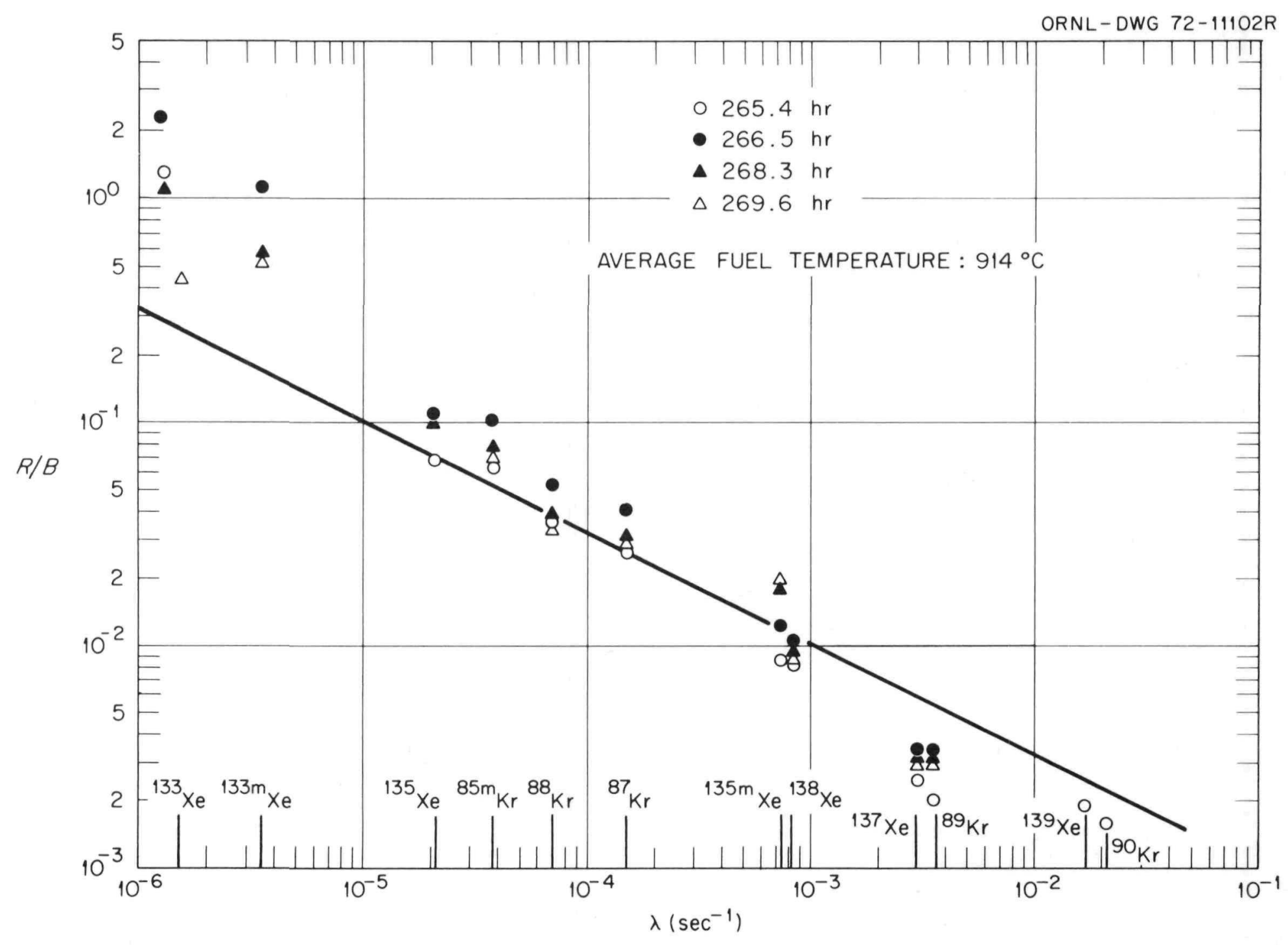

Fig. 16. Experiment D. R/B values during third steam injection. 


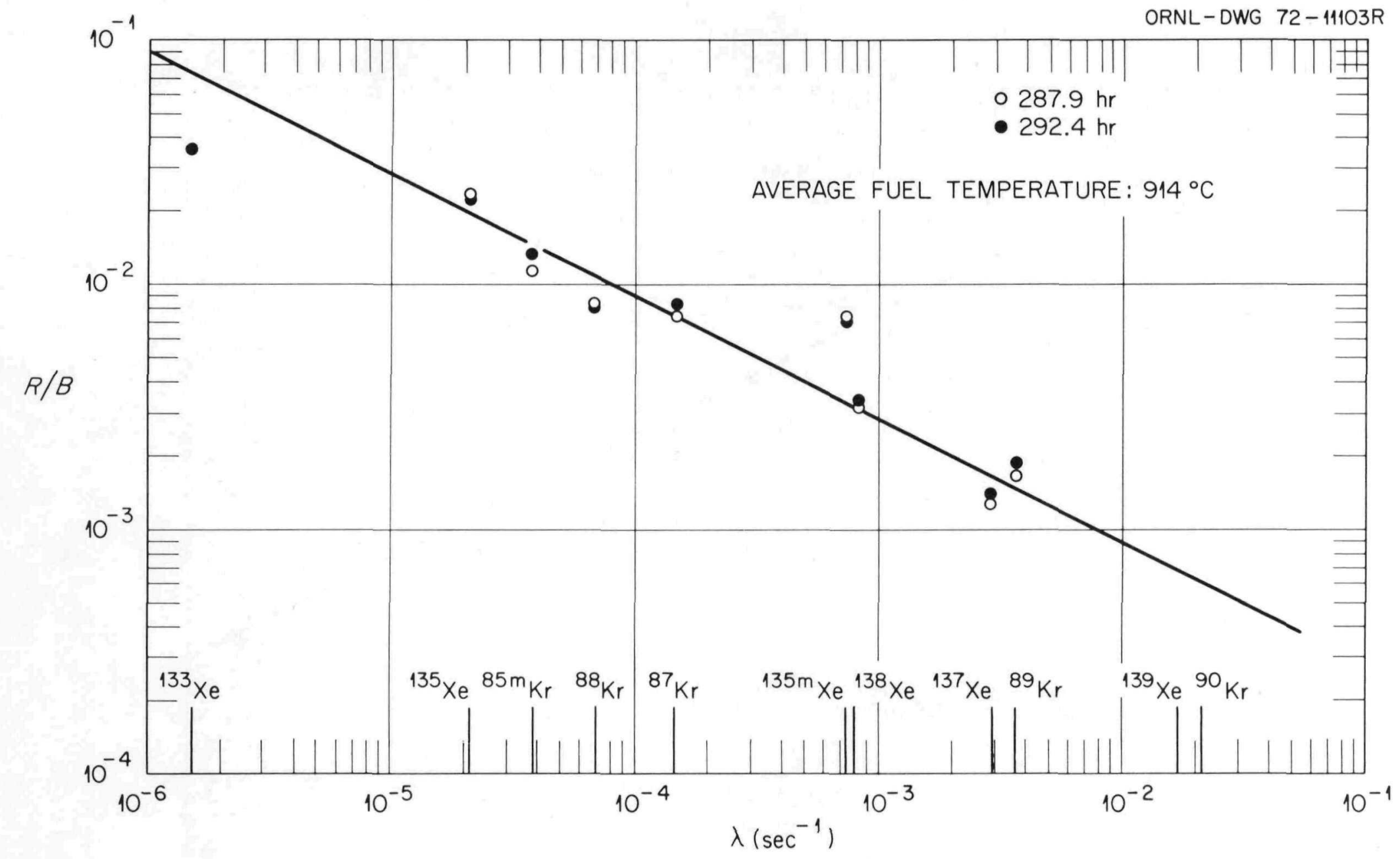

Fig. 17. Experiment D. R/B values after third steam injection. 


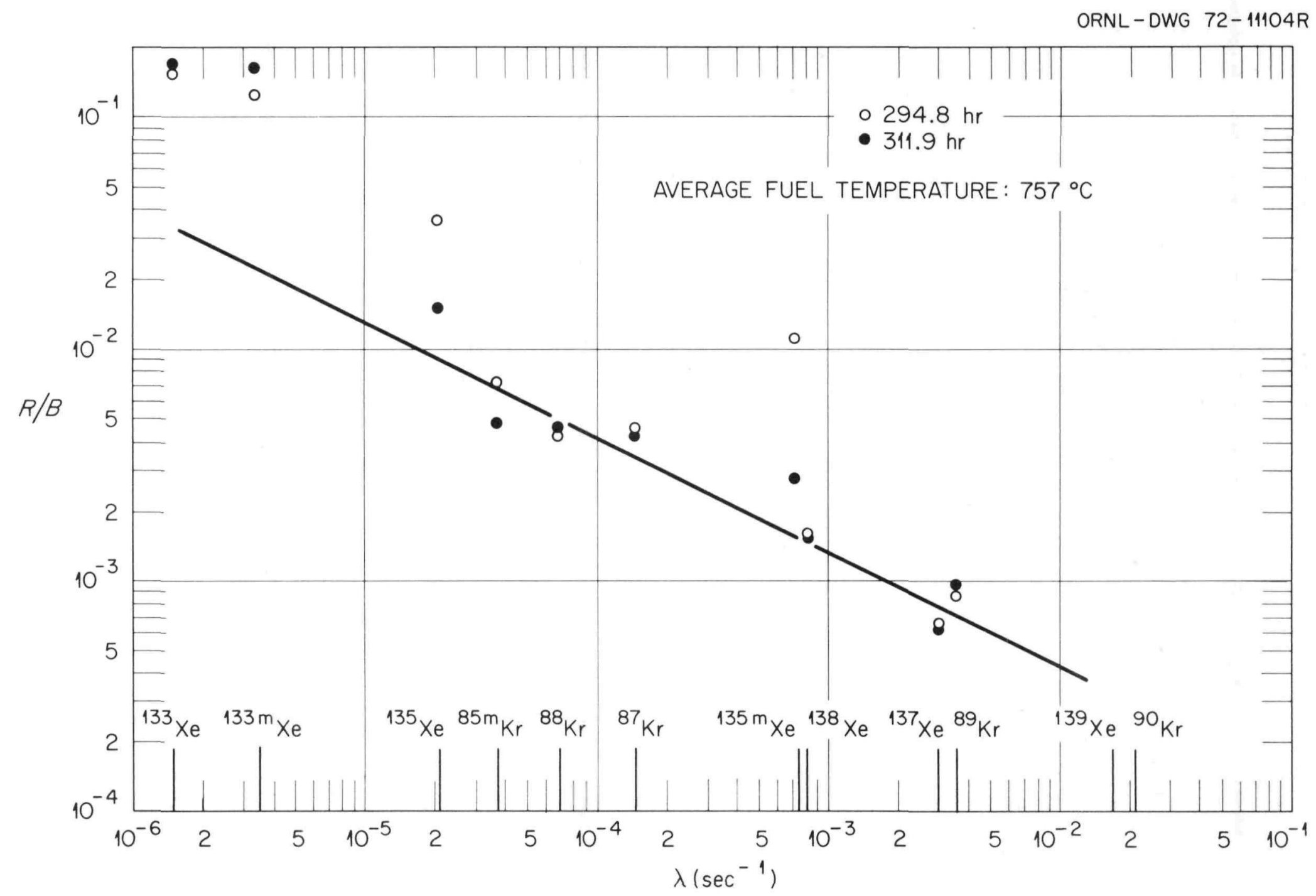

Fig. 18. Experiment D. R/B values prior to fourth steam injection. 


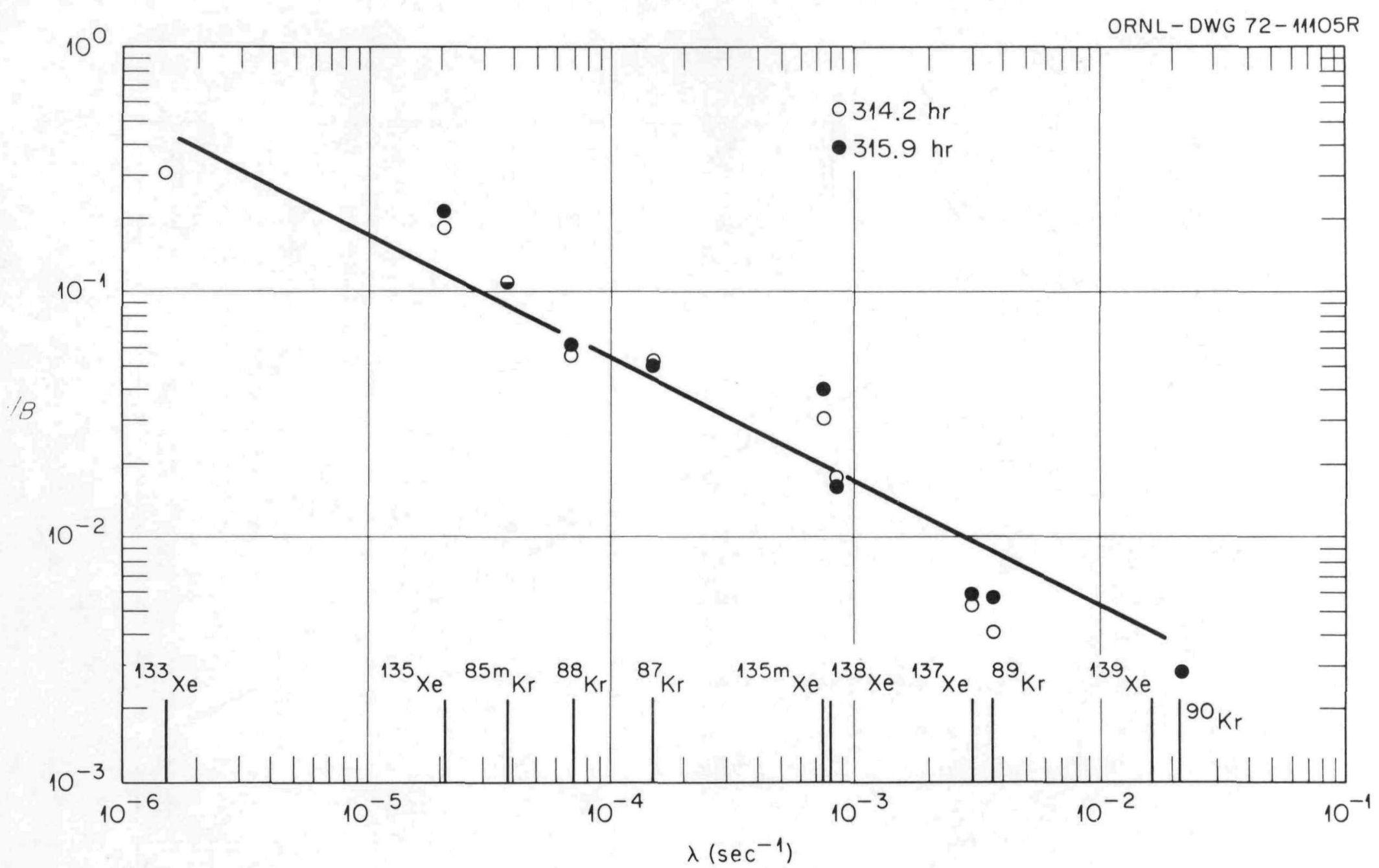

Fig. 19. Experiment D. R/B values during fourth steam injection. 


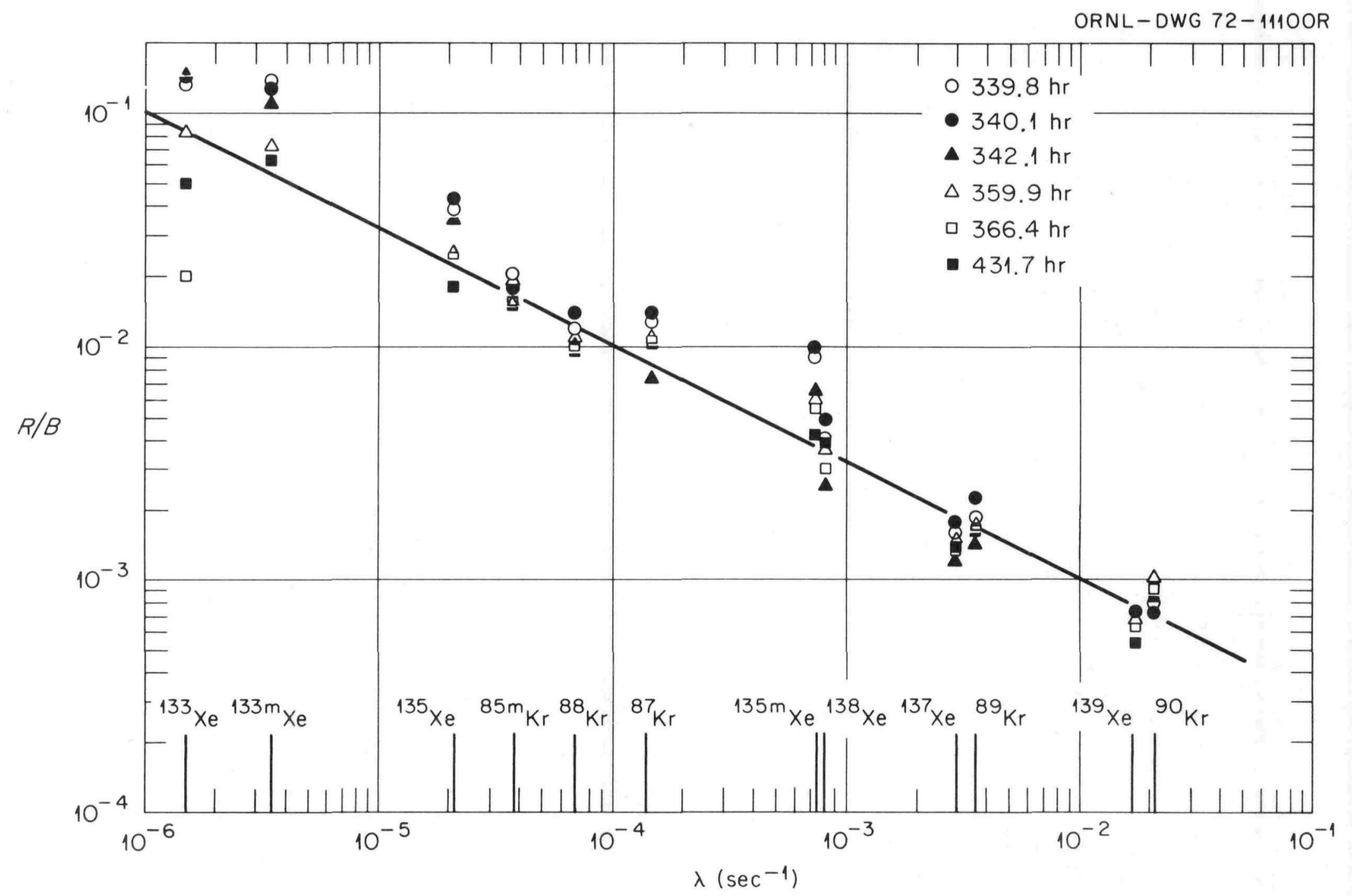

Fig. 20. Experiment D. R/B values after fourth steam injection. 


\subsection{Solid Fission Product Distributions}

In view of the large increase in gas release during Experiment D, an evaluation was made of the extent to which other fission products were released. Postirradiation examination of the model fuel element indicated that essentially all of the carbon matrix of the fuel pellet had been removed and severe particle breakage had occurred. The fuel residue was sieved and the fractions were identified visually as: (1) coarse material consisting of small chunks of the original fuel pellet, (2) coated $\mathrm{ThO}_{2}$ particles, (3) coated $\mathrm{UC}_{2}$ particles and (4) a fine $(<177-\mu \mathrm{m}$ micrometers) rubble. The distribution of uranium and thorium in each of these fractions is summarized in Table 3. The finesieved material, which was 70 wt \% uranium, accounted for approximately $25 \%$ of the original uranium inventory. This rubble probably resulted from the disintegration of exposed $\mathrm{UC}_{2}$ cores during conversion to $\mathrm{UO}_{2}$ by steam. The uranium contamination in the $\mathrm{ThO}_{2}$ sieve fraction was probably caused by $U_{2}$ particles that were not eliminated by sieving and uranium cores which were observed to penetrate into the coatings of intact $\mathrm{ThO}_{2}$ particles. The results of the analysis for the fine-sieve fraction and the observation of many broken particles in the $\mathrm{UC}_{2}$ sieve fraction indicate that under the severe conditions of this experiment probably greater than $30 \%$ of the $\mathrm{UC}_{2}$ particles were broken.

Table 3. Uranium and thorium distributions in Experiment D

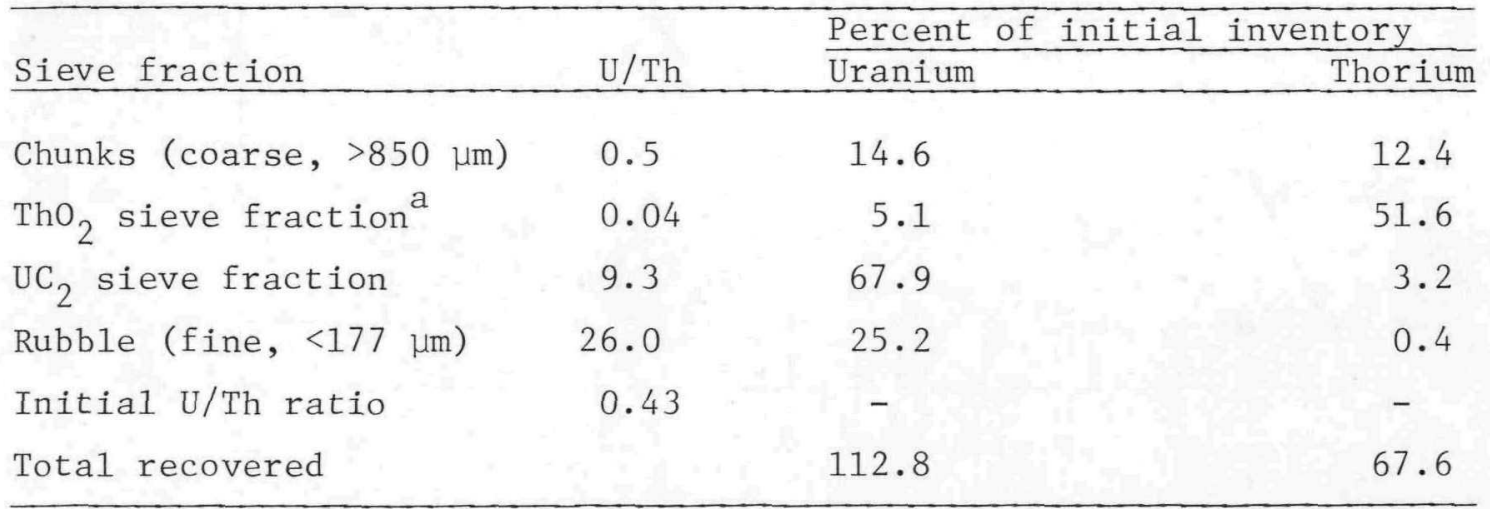

${ }^{\mathrm{a}}$ Some sample 1ost. 
${ }^{141} \mathrm{Cistributions}$ of ${ }^{131} \mathrm{I},{ }^{137} \mathrm{Cs},{ }^{89} \mathrm{Sr},{ }^{140} \mathrm{Ba},{ }^{103} \mathrm{Ru},{ }^{95} \mathrm{Zr}$, and The excess cesium found may be indicative of hot-cell contamination. The deficiency of ${ }^{103} \mathrm{Ru}$, on the other hand, is probably due to uncertainties in the analyses for this species. Except for iodine, the nuclides investigated appeared to have been retained effectively by the fuel element. Iodine-131, however, was transported throughout the primary system under the conditions of the experiment.

Table 4. Fission product distributions in Experiment $\mathrm{D}^{\mathrm{a}}$

\begin{tabular}{|c|c|c|c|c|c|c|c|}
\hline \multirow[b]{2}{*}{ Location } & \multicolumn{7}{|c|}{ Percent of calculated production } \\
\hline & ${ }^{131_{I}}$ & $137 \mathrm{Cs}$ & ${ }^{89} \mathrm{Sr}$ & $140 \mathrm{Ba}$ & ${ }^{103} \mathrm{Ru}$ & $95 \mathrm{Zr}$ & ${ }^{141} \mathrm{Ce}$ \\
\hline $\begin{array}{l}\mathrm{UC}_{2} \text { sieve } \\
\text { fraction }\end{array}$ & 12.1 & 59.7 & 65.3 & 53.3 & 45.5 & 49.7 & 46.3 \\
\hline $\begin{array}{l}\mathrm{ThO}_{2} \text { sieve } \\
\text { fraction }\end{array}$ & 4.3 & 7.8 & 10.2 & 17.5 & 4.7 & 5.8 & 5.6 \\
\hline $\begin{array}{l}\text { Fine rubble } \\
\text { sieve fraction }\end{array}$ & 15.0 & 48.5 & 19.1 & 17.8 & 2.1 & 17.7 & 22.3 \\
\hline Graphite casing & 0.3 & 1.9 & 0.5 & 0.3 & 0.4 & 0.3 & 0.3 \\
\hline $\begin{array}{l}\mathrm{Al}_{2} \mathrm{O}_{3} \text { caps and } \\
\text { reaction chamber }\end{array}$ & 0.5 & 0.2 & - & - & - & - & - \\
\hline $\begin{array}{l}\text { Stainless steel } \\
\text { exit lines }\end{array}$ & 9.4 & - & - & - & - & - & - \\
\hline $\begin{array}{l}\mathrm{H}_{2} \mathrm{SO}_{4} \text { dryers in } \\
\text { analytical train }\end{array}$ & 0.4 & - & - & - & - & - & - \\
\hline Total recovered & 42.0 & 118.1 & 95.1 & 88.6 & 52.7 & 73.2 & 74.5 \\
\hline
\end{tabular}

Where no value is presented, the concentration of the fission product is below the limits of detection. 


\subsection{Fue1 Particle Behavior}

Hot-cel1 post-test examination of each mode1 fuel element indicated that, except for Experiment B, oxidation had removed most of the carbon matrix of the fuel pellet, and only a bed of loose particles remained. Visual examination of the particles revealed that some corrosion of the pyrocarbon had occurred by a pitting mechanism. Debonded, coated $\mathrm{UC}_{2}$ particles recovered from Experiment $\mathrm{C}$ and similarly debonded, coated $\mathrm{ThO}_{2}$ particles recovered from Experiment $\mathrm{D}$ are shown on Fig. 21. In both instances, several examples of pitting-type corrosion can be seen. In many cases, attack of the fuel particle coating by steam resulted in a fragmentation of the coatings, leaving bare kernels. (The $\mathrm{ThO}_{2}$ coatings retained their spherical shape.) Several examples of coating fragments from Experiment D are shown in Fig. 22. A bare $\mathrm{ThO}_{2}$ core can be seen in the upper right-hand corner. Sieving the debonded fuel residue always yielded coating fragments.

The post-test examinations also revealed a fuel-particle failure mechanism which was unexpected. During the postirradiation examination of the fuel particles recovered from Experiments $C$ and D, protuberances on several $\mathrm{ThO}_{2}$ particle coatings were noticed. One such particle, from Experiment D, is shown isolated in Fig. 23.

Photomicrographs of polished sections of these types of particles are displayed in Figs. 24 and 25. Significantly, there was no preferred orientation for this type of attack, as can be seen in Fig. 25; moreover, the attack occurred external to the particle. Thus, it was not caused by the core leaving the coating under the influence of a thermal gradient. Electron-microprobe analyses of the protuberances indicated that they were a uranium compound. The results of visible, polarized light and etching techniques which were performed to assign chemical compositions to the uranium-containing phases are displayed in Fig. 26. The bulk of the attacking species is $\mathrm{UO}_{2}$. A transition region is located closer to the pyrocarbon surface Adjacent to the pyrocarbon is located a thin layer of $\mathrm{UC}_{2}$. The conversion of $\mathrm{UO}_{2}$ to the carbide has been shown to proceed at a measurable rate only at temperatures above those expected in these 
ORNL DWG 78-9652R
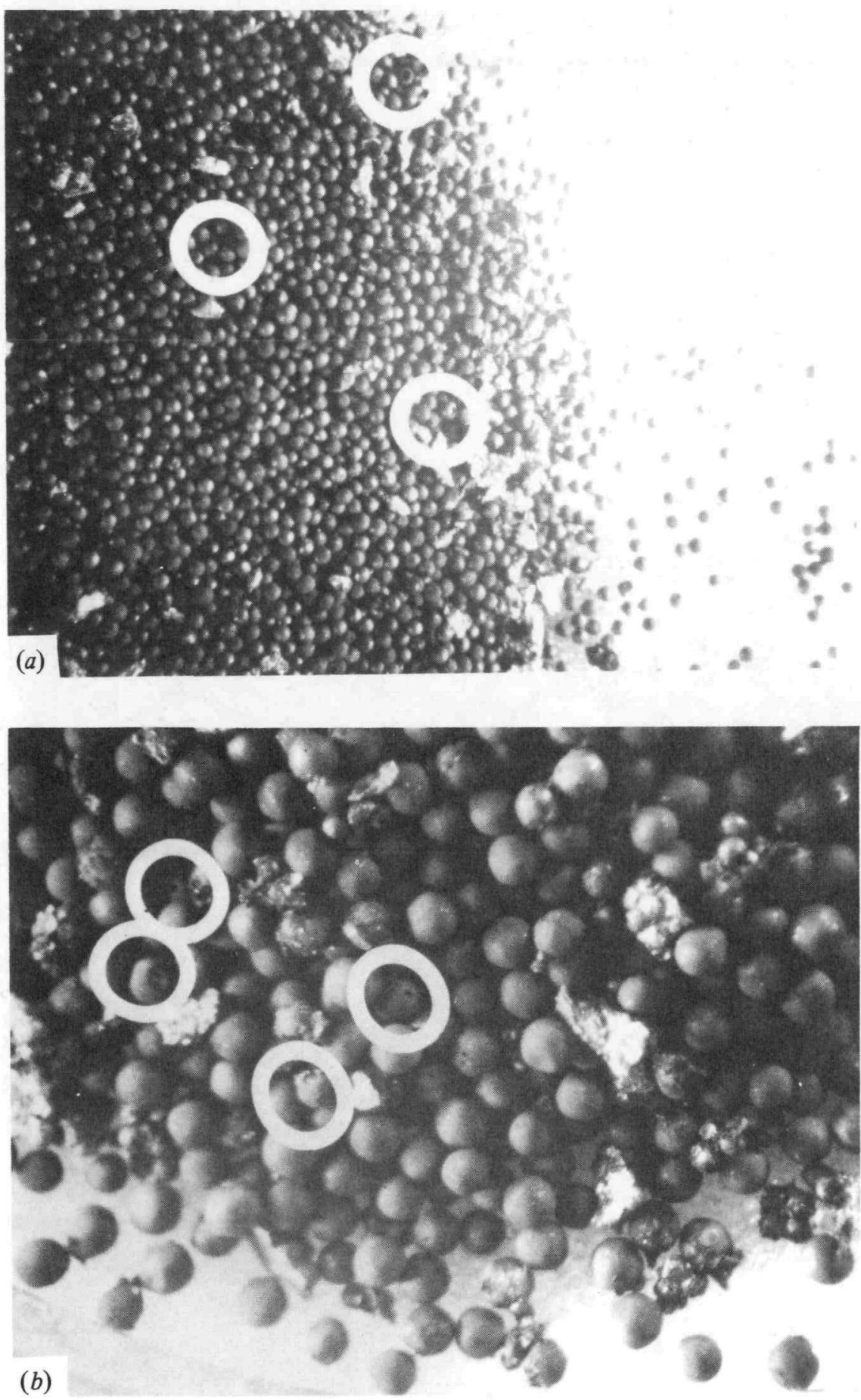

Fig. 21 (a) Debonded pyrolytic carbon-coated $\mathrm{UC}_{2}$ fuel particles recovered from Experiment C; (b) debonded pyrolytic carbon-coated $\mathrm{ThO}_{2}$ particles recovered from Experiment D. 


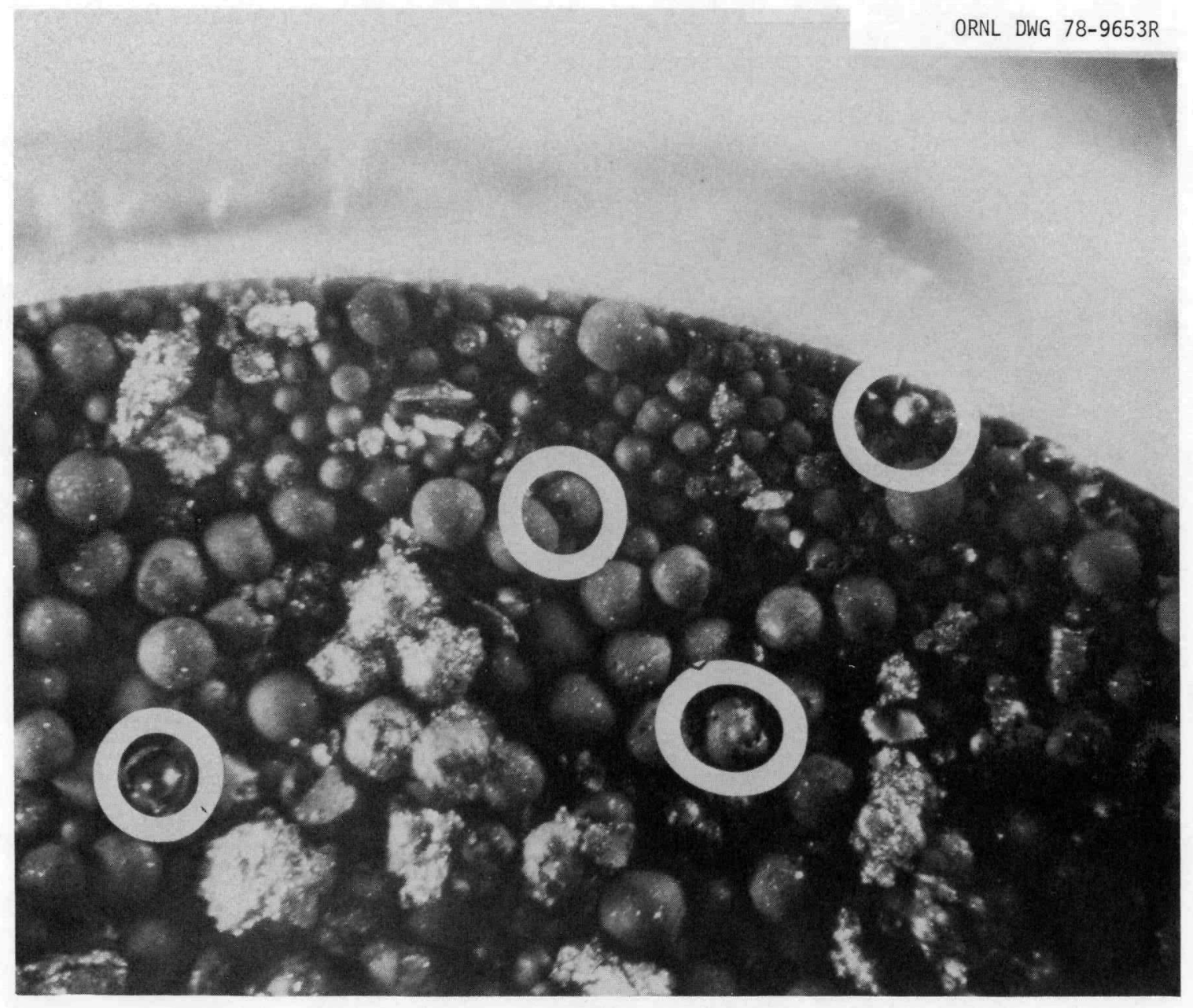

Fig. 22. Fue1 debris recovered from Experiment D. 


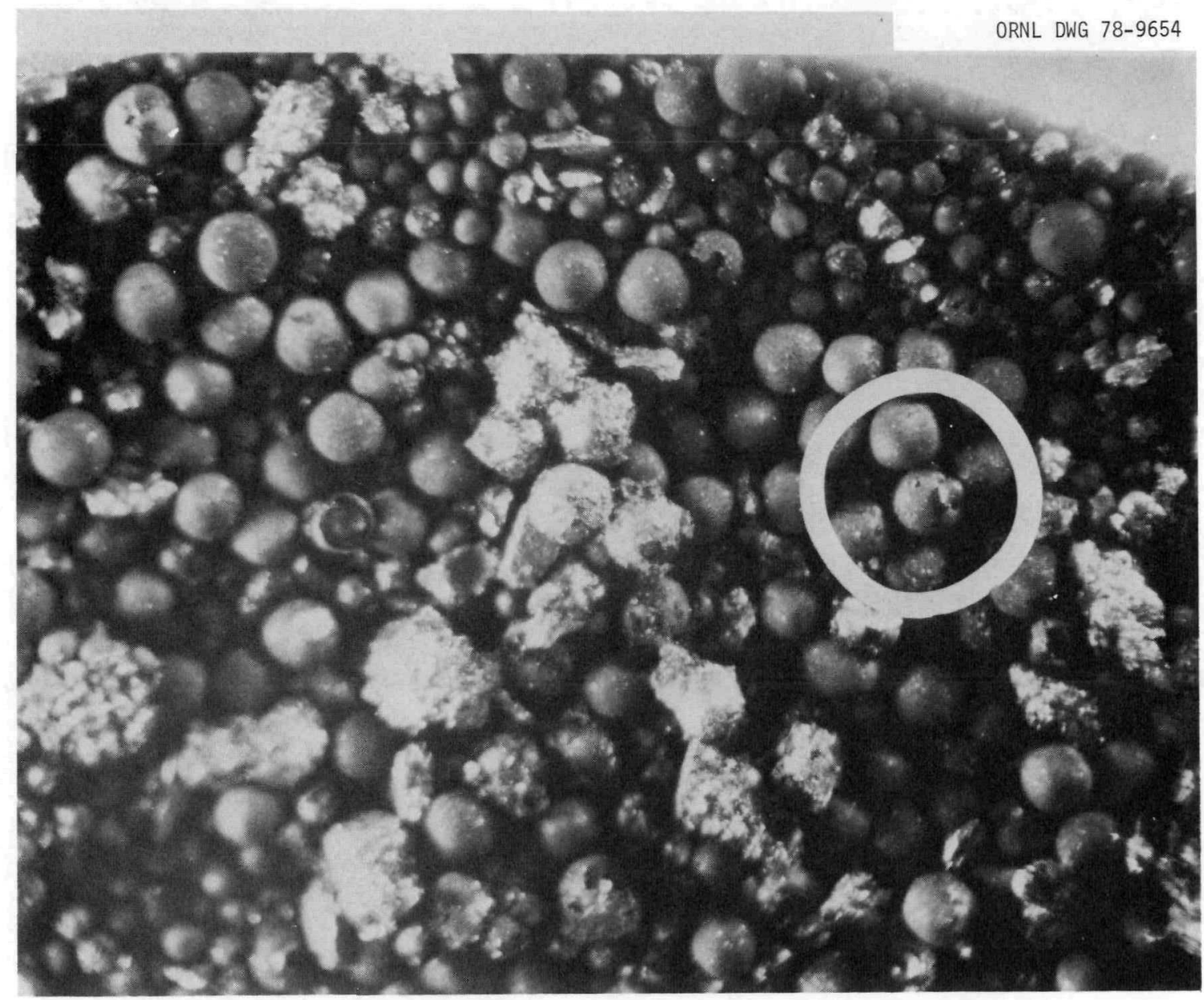

Fig. 23. Debris recovered from Experiment D showing fuel attack of a particle coating. 
ORNL DWG 78-9655

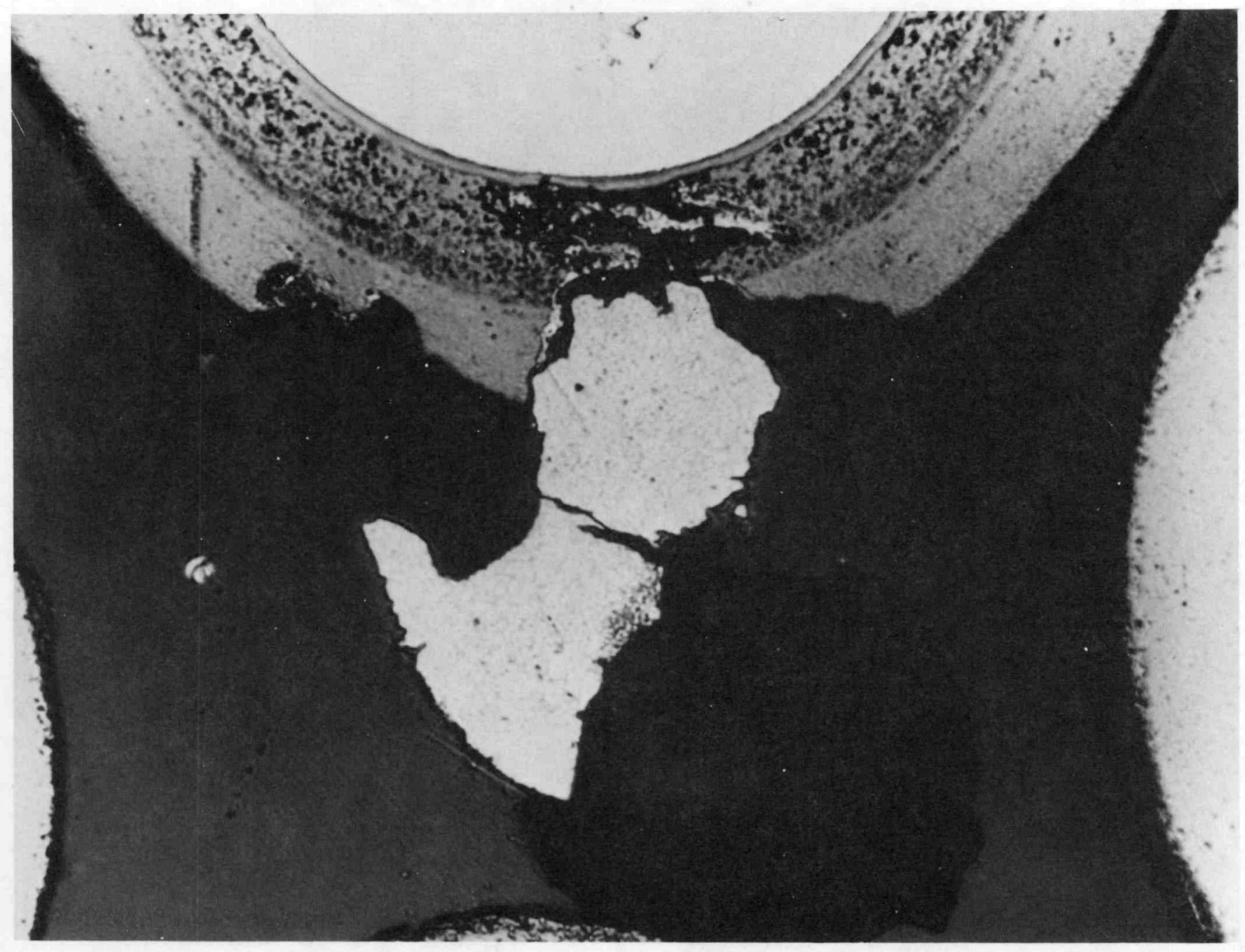

Fig. 24. Photomicrograph of fuel attack of a particle coating from material recovered from Experiment D. 


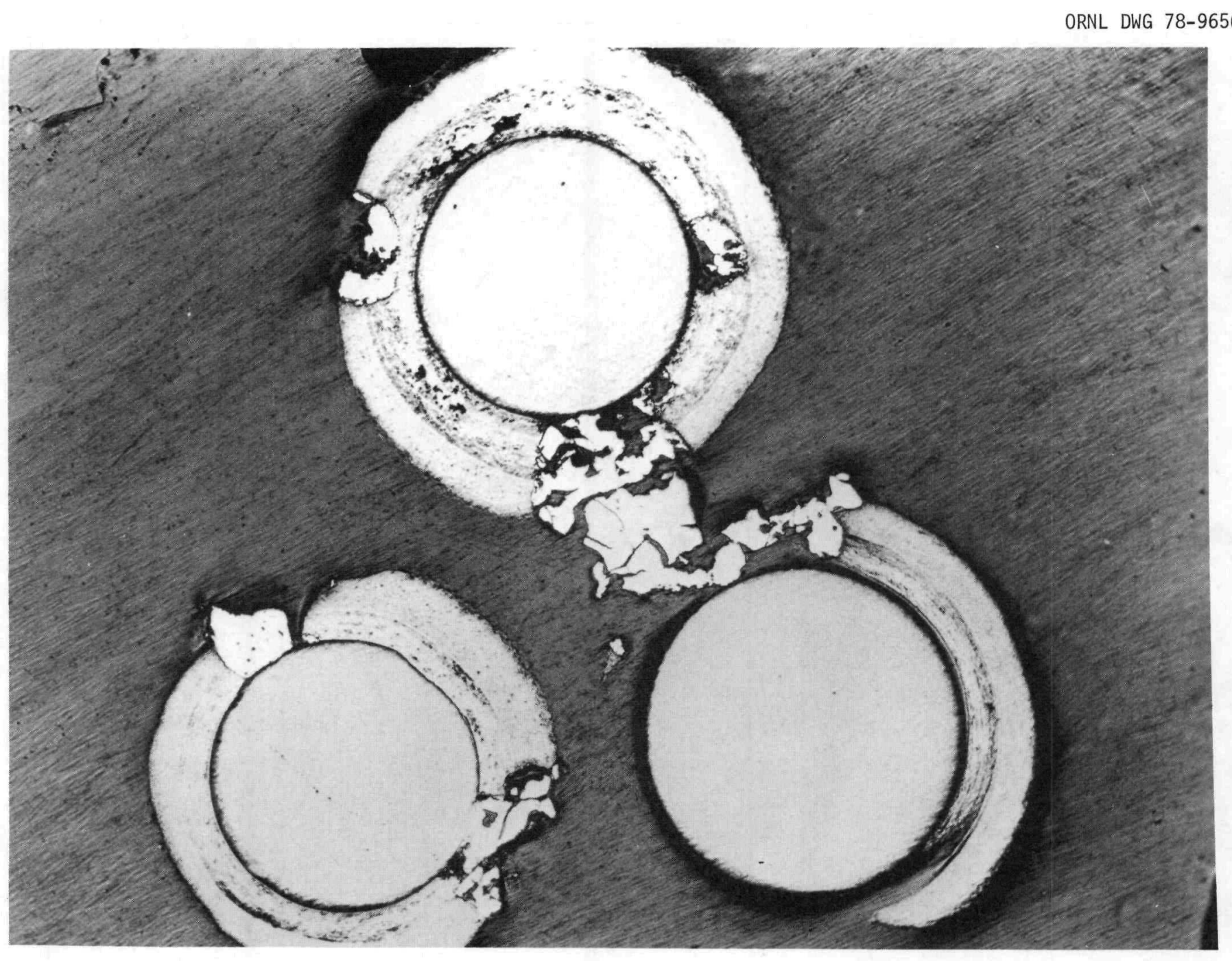

Fig. 25. Photomicrograph of fuel attack of particle coatings from material recovered from Experiment C. 
ORNL DWG 78-9657
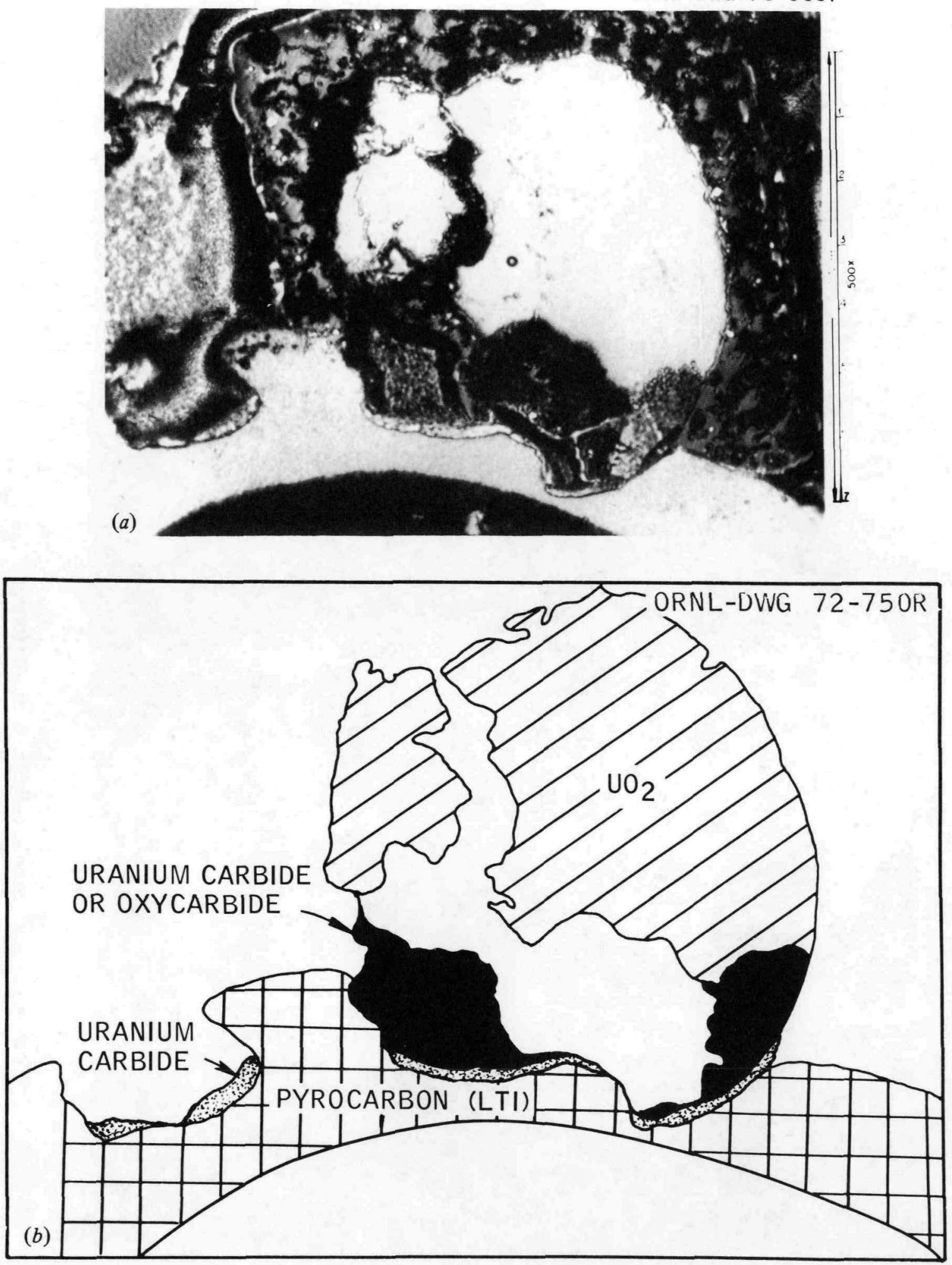

Fig. 26. Photomicrograph of (a) fuel attack of the pyrolytic carbon coating of a $\mathrm{ThO}_{2}$ particle and (b) the phases involved. 
experiments. ${ }^{5}$ However, the fuel in individual unbonded particles could operate at temperatures substantially above those presented in

Table 2. A scanning electron microscope view of a $\mathrm{ThO}_{2}$ particle with a strongly adherent fragment of uranium is shown in Fig. 27 (a); a fragment on the coating surface is shown at higher magnification in Fig. 27 (b). The fragments shown here appear to be broken pieces of a uranium kernel. However, on the same particle evidence of localized melting was also observed. What appears to be a uranium shard that had been melted and then cooled down is displayed in Fig. 28.

A plausible sequence of events that can explain this apparently accelerated mode of fuel failure is: (1) steam oxidation of sufficient binder has occurred so that the particles are partially loose; pitting corrosion of some coatings by steam, catalyzed by uranium and/or fission products, cause them to fail, in turn causing some of the bare kernels to come in contact with other coatings; (3) the bare $\mathrm{UC}_{2}$ kernel is oxidized by steam to $\mathrm{UO}_{2}$; (4) during the period between steam exposures, the $\mathrm{UO}_{2}$ fragments slowly reconvert to the carbide or oxycarbide in dry helium, thus attacking the pyrolytic carbon coating in the process. Further steam ingresses would then reoxidize the $\mathrm{UC}_{2}$ so that the cycle could be repeated.

\subsection{Fuel Element Oxidation}

The experiments were generally not conducted under the timetemperature-steam concentration conditions that had been originally designated. Difficulty was experienced in maintaining uniform steam concentrations because of condensation which occurred at cold spots in the coolant lines. Two of the tests were aborted since leaks developed in the containment, and in one case the test was terminated prematurely because of the high temperature at the top of the primary containment. Temperature control under both steam and no-steam conditions was usually good; the three thermocouples that monitored the graphite casing temperature ordinarily yielded temperatures which agreed within $20^{\circ} \mathrm{C}$. 

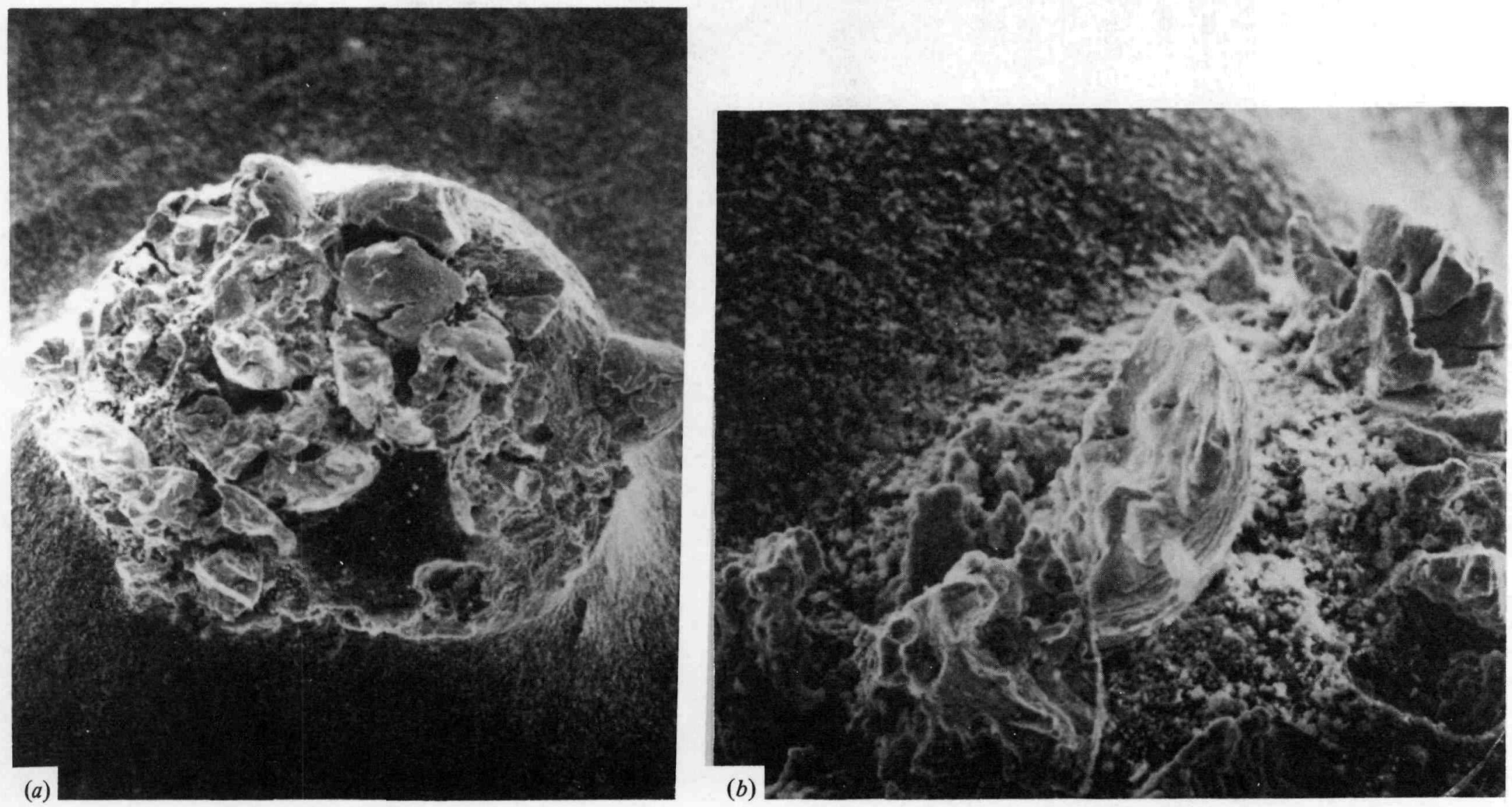

Fig. 27. Scanning electron microscope view of (a) uranium attack of a pyrolytic carbon coating and (b) uranium fuel fragment on a pyrolytic carbon surface. 
ORNL DWG 78-9659

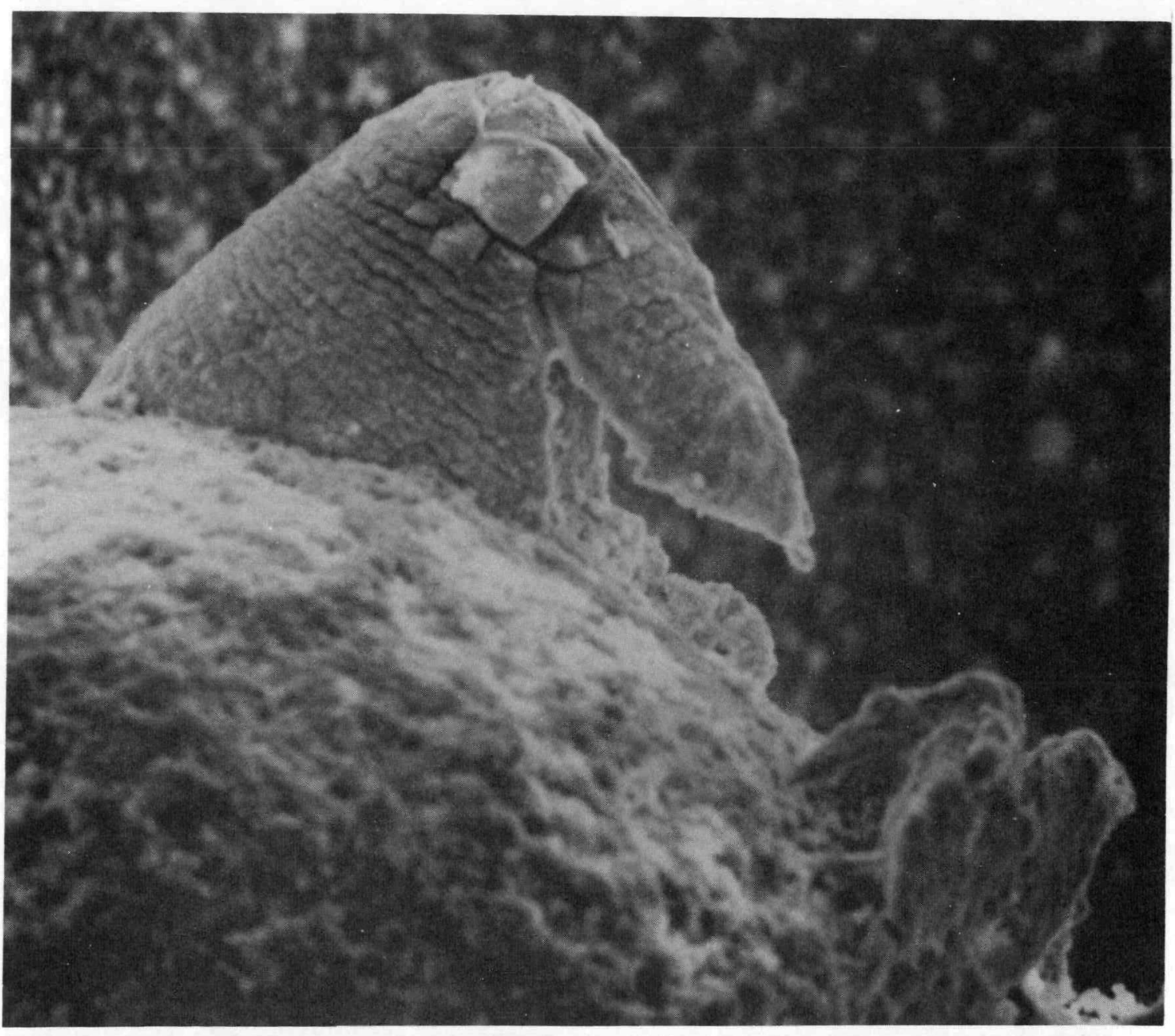

Fig. 28. Scanning electron microscope view of a once-molten uranium fuel particle on a pyrolytic carbon surface. 
The amounts of carbon oxidized were determined using three different methods. An infrared analyzer system was employed to continuously monitor $\mathrm{CO}$ in the effluent stream. The analyzer had a dynamic range of 0.01 to $1 \% \mathrm{CO}$ in helium; it was calibrated prior to each test. As noted previously, this instrument also proved to be extremely useful in detecting blockages of the primary gas lines. These blockages, which were caused by steam condensation at localized cold spots in the 1/8-in.-OD inlet lines, resulted in oscillations of the $\mathrm{CO}$ concentration in the effluent stream.

The second method for determining oxidation of the model fuel element involved the use of Ascarite to trap the carbon oxides as $\mathrm{CO}_{2}$. During each experiment, sets of traps were operated in such a way that the effluent coolant stream was sampled before, during, and after each steam exposure. These traps, along with a set employed as a control, were subsequently analyzed for both $\mathrm{CO}_{2}$ and ${ }^{14} \mathrm{C}$ content.

The third independent measurement of the extent of fuel element corrosion involved weight determinations of the fuel residue and empty graphite casing in a hot cell after disassembly of the capsule.

These measurements were then employed to normalize the results derived from the two previously described methods.

The mass spectrometer system was employed primarily to monitor the purity of the primary coolant when no steam was present. The instrument became erratic, however, when steam was introduced into the system, because of the fluctuations in coolant flow noted above. Blood and Malinauskas ${ }^{6}$ demonstrated that the bonded fuel pellets used in these experiments would undergo significant weight loss simply by heating, with no oxidation, as a result of improper heat treatment during fabrication. Hence, weight losses which are reported subsequently cannot be unambiguously ascribed to oxidation. An additional complication involves uncertainties in temperature due to the loss of the fuel-pellet matrix carbon; as indicated previously, carbon loss in Experiment A decreased the average thermal conductivity of the fuel element by about a factor of 2. Because of these factors, an attempt to quantitatively describe the observed graphite losses could not be realized. 


\subsubsection{Experiment A}

This experiment, which was employed primarily to commission the facility, differed from the others in three major respects. First, the fuel particles contained SiC coatings as well as pyrolytic carbon coatings. Secondly, provision was made for insertion of a thermocouple into the center of the fuel body. Thirdly, the graphite casing contained an uncharacteristica11y high iron content for H-327 graphite. The material was incorrectly certified to be equivalent to the graphite employed in the fabrication of Fort St. Vrain HTGR fuel elements; it was in fact representative of a preproduction run of $\mathrm{H}-327$ graphite containing localized iron which caused it to oxidize by a severe pitting mechanism. This graphite was observed to react 10 to 15 times more rapidly with steam than another sample of $\mathrm{H}-327$ graphite; this latter material is stated to be more representative of Fort St. Vrain HTGR core material. ${ }^{7}$ The consequences of localized concentrations of iron are evident in the post-test photographs of the graphite casing of the fuel element used in Experiment A; these are presented in Figs. 29 and 30. The cumulative weight losses observed are summarized in Table 5 .

The effects of iron in the graphite were not confined to the graphite casing. Electron microprobe scans of pits in the pyrolytic carbon coatings revealed iron impurity at the bases of the pits, but nowhere else. Two such iron-containing areas are displayed in Fig. 31. Furthermore, once the pyrolytic carbon coating had been removed, it appeared that the iron impurity could also penetrate the SiC layer. However, iron was found only in the SiC layers of particles whose SiC was exposed as a result of oxidation of the outer pyrolytic carbon coating.

Disassembly of the fuel element after conclusion of the in-pile testing revealed that the fuel poured easily from the casing, since $20 \%$ of the carbon had been removed. Significantly, kernels of $\mathrm{UC}_{2}$ particles had neither hydrolyzed nor oxidized during steam exposure or metallographic polishing. Although the incidence of fuel particle failure was greater than expected, it is unclear whether the iron impurity in the graphite influenced this behavior. 
ORNL DWG 78-9660
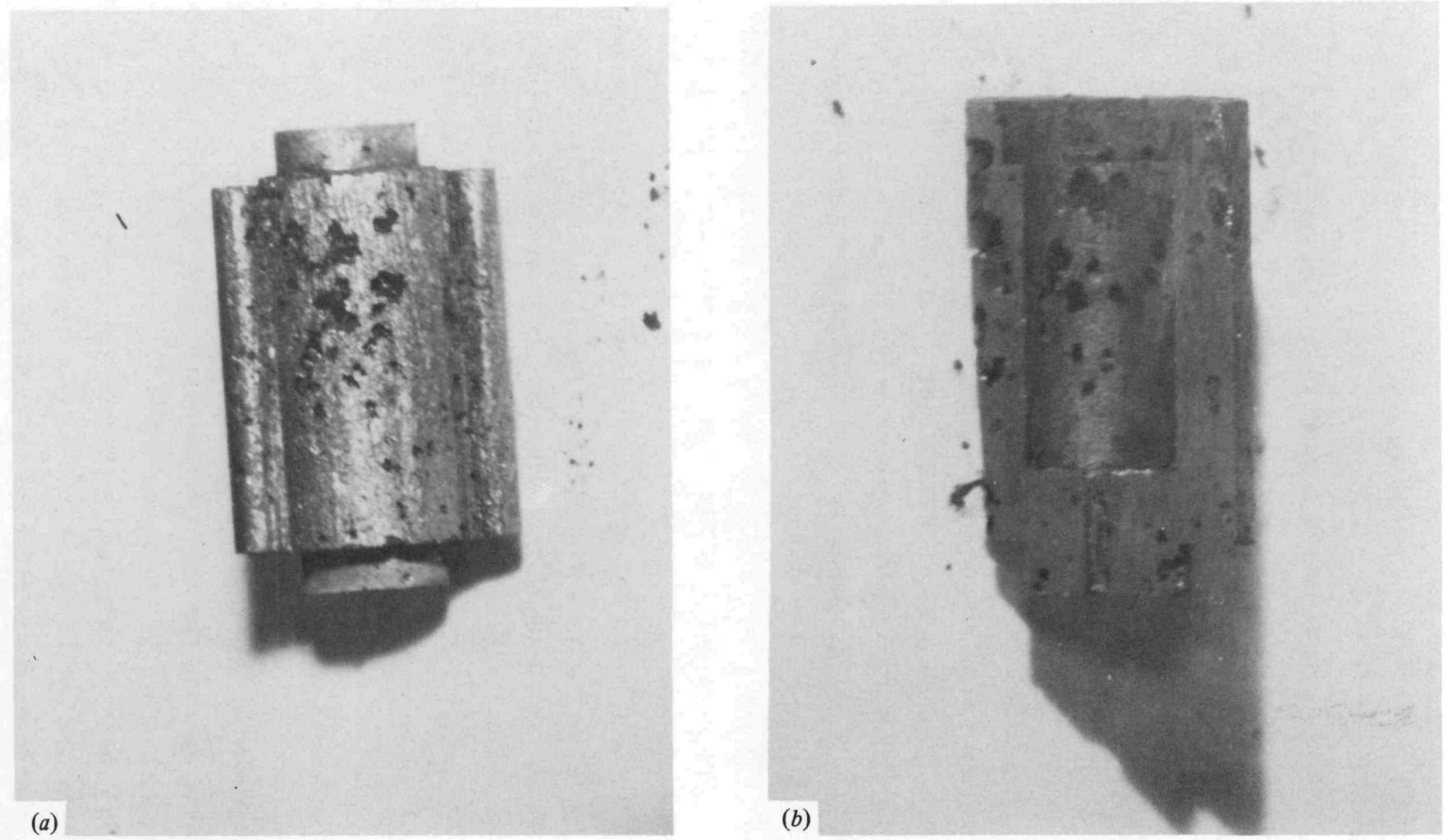

Fig. 29. Graphite fuel element casing after exposure to steam in Experiment A. (a) External view; (b) view of the internal surface of the casing. 
ORNL DWG 78-9661

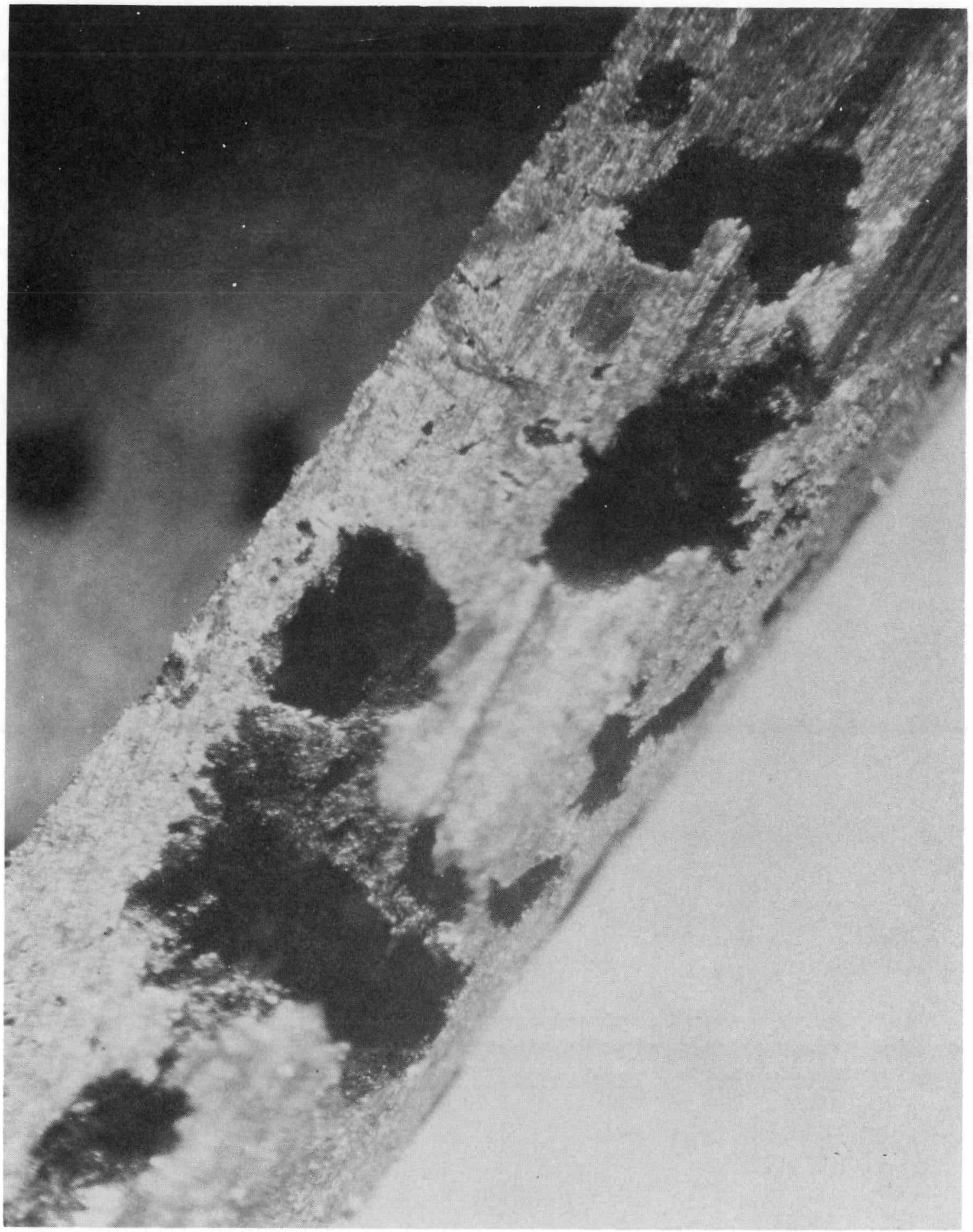

Fig. 30. Post-test cross-sectional view of the casing wall of the graphite fuel element of Experiment A. 
Table 5. Steam-graphite Experiment $\mathrm{A}^{\mathrm{a}}$

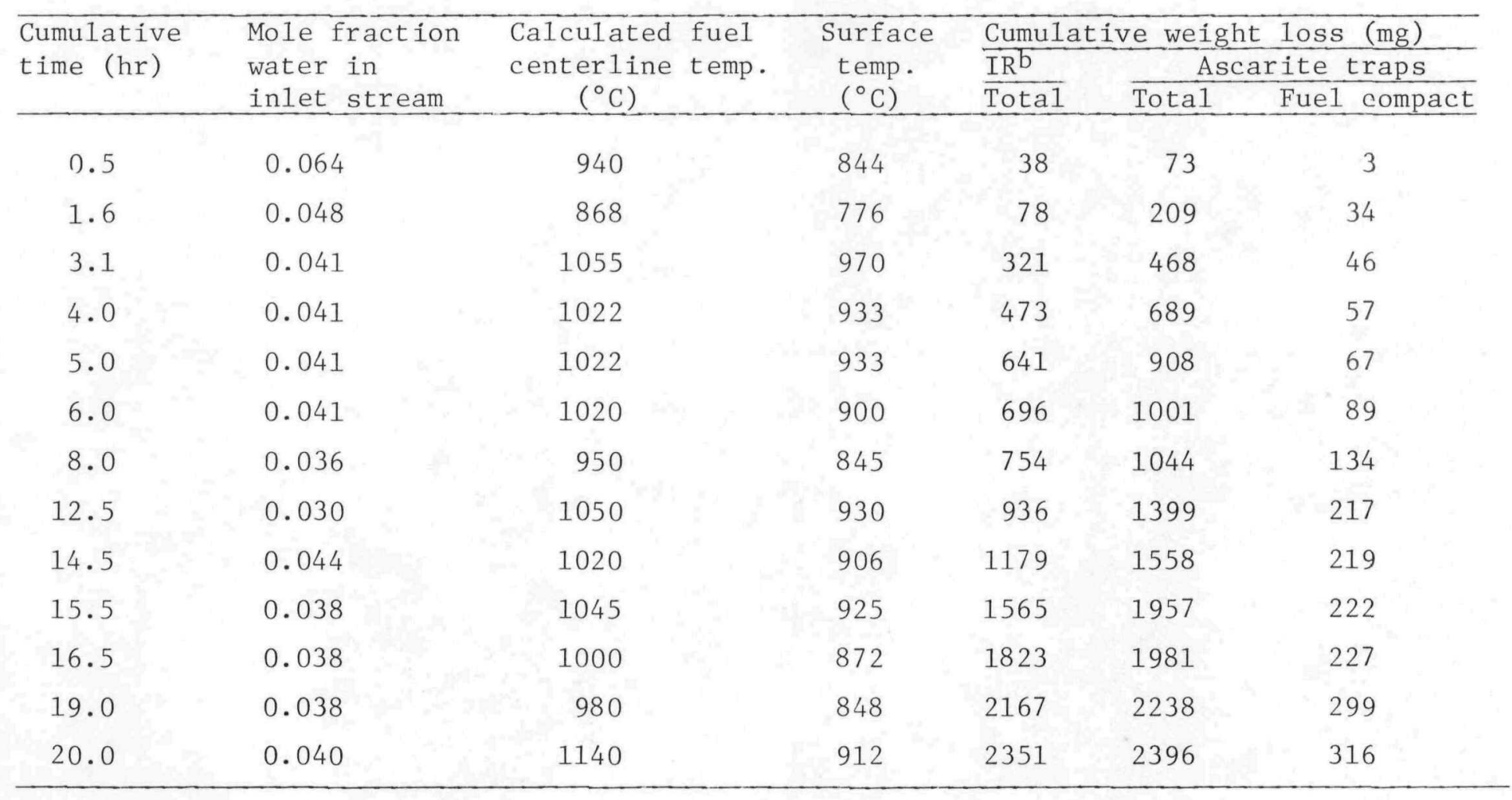

a Postirradiation weight loss (mg): casing, 2202; fuel rod, 373; total, 2395.

${ }^{\mathrm{b}}$ Infrared analyzer. 

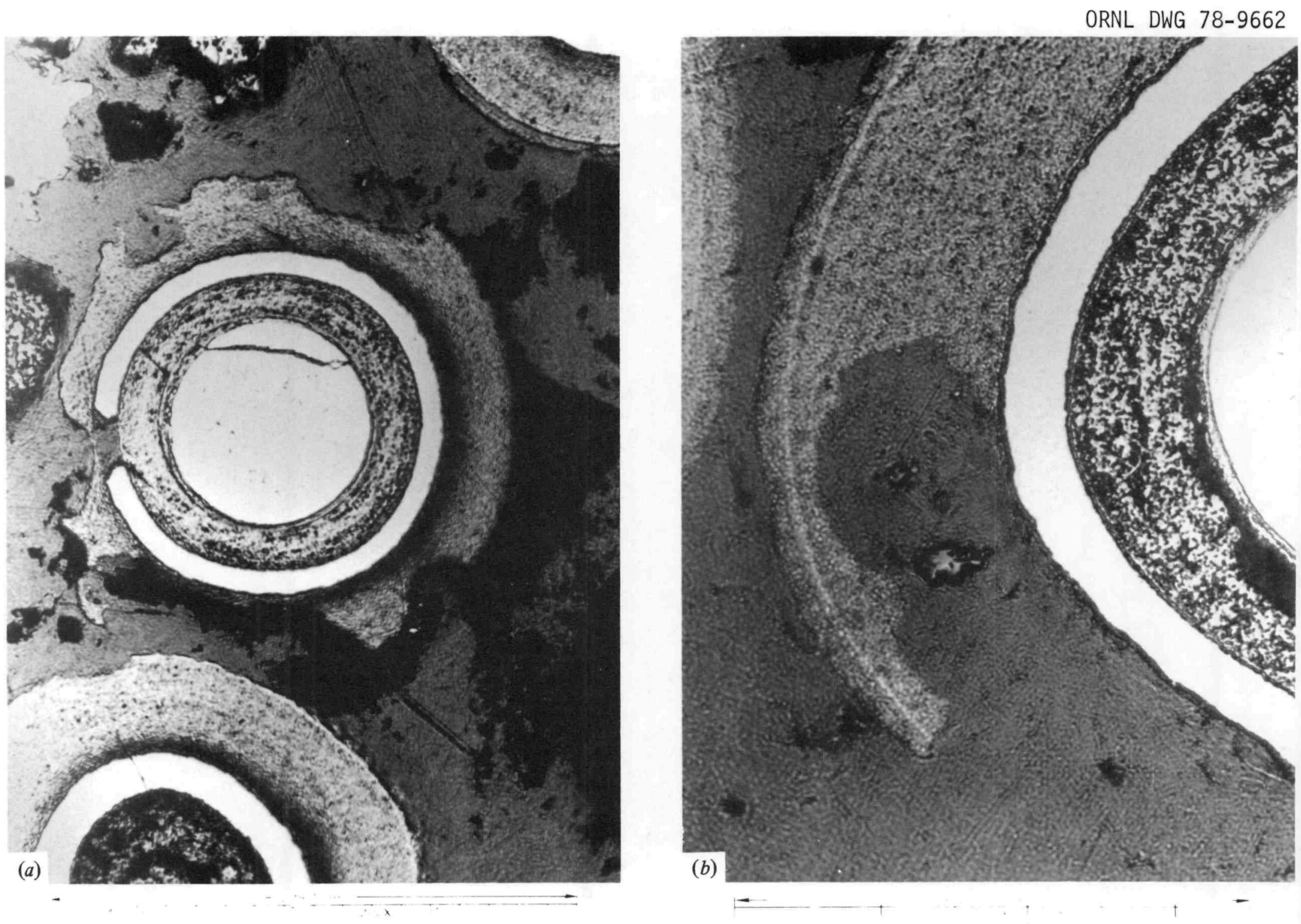

Fig. 31. Experiment A, (a) location of iron on a coated fuel microsphere and (b) location of iron in a deep pit. 


\subsubsection{Experiment B}

Only pyrolytic carbon-coated fuel particles were contained in the bonded pellet of the Experiment B fuel element, and the casing was fabricated from $\mathrm{H}-327$ graphite of low iron impurity. The only similarity between this fuel element and the one used in Experiment A was the inclusion of a thermocouple to monitor the fuel centerline temperature. Leakage in the containment, however, necessitated the premature termination of the test. Cumulative carbon losses determined in the test are given in Table 6 .

The fuel pellet, as removed from the graphite casing after steam exposure of $10.2 \mathrm{hr}$, is displayed in Fig. 32(a); the casing, displayed in Fig. 32(b), shows a lack of oxidative pitting.

Table 6. Steam-graphite Experiment $\mathrm{B}^{\mathrm{a}}$

\begin{tabular}{llcccc}
\hline $\begin{array}{l}\text { Time } \\
(\mathrm{hr})\end{array}$ & $\begin{array}{l}\text { Mole fraction } \\
\text { water in inlet } \\
\text { stream }\end{array}$ & $\begin{array}{c}\text { Fuel centerline } \\
\text { temp. }\left({ }^{\circ} \mathrm{C}\right)\end{array}$ & $\begin{array}{c}\text { Surface } \\
\text { temp. } \\
\left({ }^{\circ} \mathrm{C}\right)\end{array}$ & $\begin{array}{c}\text { Cumulative weight loss (mg) } \\
\text { Fuel rod }\end{array}$ & $\begin{array}{c}\text { Whole element } \\
3.4\end{array}$ \\
\hline 0.04 & 1060 & 700 & 17 & 56 \\
6.6 & 0.03 & 1060 & 700 & 42 & 83 \\
8.8 & 0.03 & 1190 & 763 & 83 & 165 \\
9.2 & 0.03 & 1240 & 788 & 98 & 219 \\
10.2 & 0.03 & 1310 & 800 & 108 & 237 \\
\hline
\end{tabular}

Postirradiation weight loss (mg): casing, 94; fuel rod, 143; tota1, 237.

\subsubsection{Experiments $\mathrm{C}$ and $\mathrm{D}$}

These two experiments utilized model fuel elements which were identical to the one employed in Experiment $B$ in every respect except that they did not contain a centerline thermocouple well. The cumulative carbon losses experienced during these two experiments are presented in Tables 7 and 8 . The state of the fuel at the conclusion of the two experiments has already been described. 

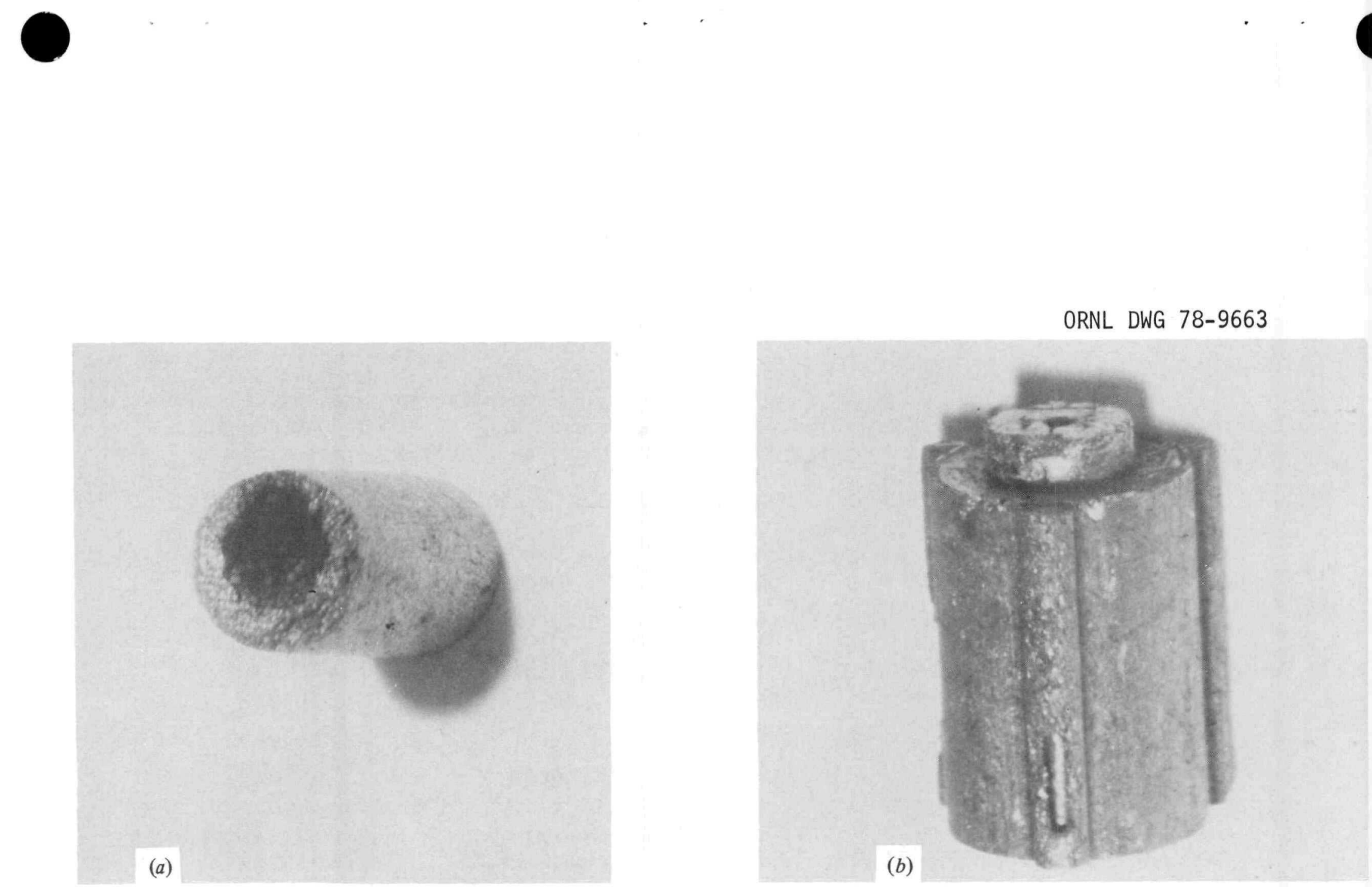

Fig. 32. Experiment B. Fuel pellet (a) and model fuel element (b) after exposure to steam. (The central hole of the fuel pellet contained a thermocouple.) 
Table 7. Steam-graphite Experiment $c^{a}$

\begin{tabular}{|c|c|c|c|c|c|}
\hline $\begin{array}{l}\text { Time } \\
\text { (hr) }\end{array}$ & $\begin{array}{l}\text { Mole fraction } \\
\text { water in inlet } \\
\text { stream }\end{array}$ & $\begin{array}{l}\text { Calculated fuel } \\
\text { centerline temp. } \\
\left({ }^{\circ} \mathrm{C}\right)\end{array}$ & $\begin{array}{c}\text { Surface temp. } \\
\left({ }^{\circ} \mathrm{C}\right)\end{array}$ & $\frac{\text { Cumulativ }}{\text { Fuel rod }}$ & $\frac{\text { weight loss (mg) }}{\text { Whole element }}$ \\
\hline 1.1 & 0.03 & 1330 & 982 & 1 & 17 \\
\hline 2.5 & 0.05 & 1330 & 982 & 4 & 44 \\
\hline 4.0 & 0.09 & 1330 & 982 & 16 & 88 \\
\hline 8.0 & 0.09 & 1330 & 982 & 83 & 288 \\
\hline 12.0 & 0.09 & 1330 & 982 & 144 & 638 \\
\hline 12.2 & 0.09 & 1060 & 800 & 150 & 663 \\
\hline 15.7 & 0.09 & 1060 & 800 & 248 & 835 \\
\hline
\end{tabular}

a Postirradiation weight loss (mg): casing, 630 (8); fuel rod, 206 (63); total, 836. Numbers in parentheses are percentages of the initial weights of graphite and carbon in fuel pellet matrix. 
Table 8. Steam-graphite Experiment $\mathrm{D}^{\mathrm{a}}$

\begin{tabular}{|c|c|c|c|c|c|}
\hline $\begin{array}{l}\text { Time } \\
\text { (hr) }\end{array}$ & $\begin{array}{l}\text { Mole fraction } \\
\text { water in inlet } \\
\text { stream }\end{array}$ & $\begin{array}{l}\text { Calculated fuel } \\
\text { centerline temp. } \\
\left({ }^{\circ} \mathrm{C}\right)\end{array}$ & $\begin{array}{c}\text { Surface temp. } \\
\left({ }^{\circ} \mathrm{C}\right)\end{array}$ & $\frac{\text { Cumulative }}{\text { Fue1 rod }}$ & $\frac{\text { ight loss (mg) }}{\text { Whole element }}$ \\
\hline 2.0 & 0.12 & 1380 & 820 & 46 & 111 \\
\hline 4.0 & 0.12 & 1380 & 820 & 160 & 214 \\
\hline 6.1 & 0.11 & 1380 & 820 & 211 & 279 \\
\hline 7.4 & 0.11 & 1380 & 820 & 247 & 345 \\
\hline 10.3 & 0.11 & 1190 & 730 & 275 & 468 \\
\hline 13.3 & 0.07 & 1190 & 730 & 283 & 552 \\
\hline 17.2 & 0.11 & 960 & 630 & 292 & 666 \\
\hline
\end{tabular}

a Postirradiation weight loss (mg): casing, 166 (2); fuel rod, 497 (126); total, 663. Numbers in parentheses are percentages of the initial weights of graphite and carbon in the fuel pellet matrix; $126 \%$ indicates that oxidation of the pyrolytic carbon coatings did take place. 
Note that significant reaction occurred in Experiment D while the surface temperature of the casing was maintained at only $630^{\circ} \mathrm{C}$; moreover, the bulk of the reaction appears to be confined to the casing. Unless catalysis by fission products or fuel fragments has effected this behavior, the result appears to be a manifestation of the oxidation of the pyrolytic carbon coatings, which are at a significantly higher temperature (probably even higher than that indicated as the fuel centerline temperature). This source of carbon would be ascribed erroneously to the casing graphite since it had not been tagged with ${ }^{14} \mathrm{C}$.

\section{CONCLUDING REMARKS}

The oxidation data obtained in the course of this study are summarized in Table 9. Even a superficial analysis of these results reveals two striking phenomena. First, the significance of catalysis by iron impurities in the graphite casing is unmistakeable. Secondly, it is clear that greater protection against steam attack is provided for the fuel by the graphite casing as the surface temperature of the graphite is increased. This is immediately apparent if the weight loss ratios of the casing to the fuel pellet for Experiments $C$ and D are compared. The data also suggest that the catalyzed oxidation of the casing similarly protects the fuel from oxidative attack, but a more detailed analysis would be required to affirm this postulate.

Gaseous fission product release increased dramatically upon the introduction of steam into the coolant stream, whereas the cessation of steam injection resulted in a pronounced, but correspondingly smaller, decrease in gaseous fission product release. The mechanism by which this phenomenon proceeds is unknown; additional testing, with both carbide and oxide fuel, appears warranted in order to elucidate the nature of the effect.

The incidence of fuel particle failure was considerably greater than anticipated; this could have been caused by improperly fabricated pyrolytic carbon coatings which fragmented readily, or by local temperatures which exceeded the calculated centerline values. Nonetheless, except for iodine and the noble gases, none of the fission products were transported beyond the fuel element in measurable quantities. 
Table 9. Summary of oxidation data

\begin{tabular}{cclcrrr}
\hline Experiment & $\begin{array}{l}\text { Duration of } \\
\text { steam exposure } \\
(\mathrm{hr})\end{array}$ & $\begin{array}{l}\text { Steam mole } \\
\text { fraction in } \\
\text { inlet stream }\end{array}$ & $\begin{array}{l}\text { Surface } \\
\left.\text { temp. ( }{ }^{\circ} \mathrm{C}\right)\end{array}$ & $\begin{array}{l}\text { Fuel centerline } \\
\text { temp. }\left({ }^{\circ} \mathrm{C}\right)\end{array}$ & $\begin{array}{c}\text { Carbon loss (mg) } \\
\text { Casing Fuel pellet }\end{array}$ \\
\hline $\mathrm{A}$ & 20.0 & $0.03-0.06$ & $776-970$ & $868-1140$ & 2202 & 373 \\
$\mathrm{~B}$ & 10.2 & $0.03-0.04$ & $700-800$ & $1060-1310$ & 94 & 143 \\
$\mathrm{C}$ & 15.7 & $0.03-0.09$ & $800-982$ & $1060-1330$ & 630 & 206 \\
$\mathrm{D}$ & 17.2 & $0.07-0.12$ & $630-820$ & $960-1380$ & 166 & 497 \\
\hline
\end{tabular}

$\mathrm{a}_{\text {Terminated }}$ prematurely because of containment leakage. 
The role of iron in catalyzing the corrosion of graphite by steam was not confined to the graphite casing; pitting attack on the pyrolytic carbon coatings was also noted. Moreover, iron was also observed to attack the SiC in those particles containing such coatings when the layers were left bare because of the loss of their pyrolytic carbon coatings. In addition to this type of coating failure, an entirely unexpected type of failure mechanism was observed. This involved attack of the pyrolytic carbon coatings by fuel kernels from already failed particles. The mode of attack appears to be a cyclic process involving the oxidation of the uranium carbide by steam and the re-formation of the carbide by reaction of the resultant oxide or oxycarbide with the pyrolytic carbon coatings.

Lastly, it must be remembered, when applying the results obtained here to large HTGR accident analyses, that these tests correspond to large steam ingresses which persist while high core temperatures are maintained for several hours. In most large, sudden, steam ingress accident scenarios, however, the core temperatures are lowered to the point of insignificant steam-graphite reaction in a matter of minutes.

\section{ACKNOWLEDGMENTS}

The authors are pleased to acknowledge the contributions of B. F. Roberts and 0 . Thomas, designers of the in-pile capsule, and G. Llewellyn, who performed the thermal analyses. H. W. Montgomery assembled the in-pile equipment, and E. L. Long, Jr., performed the postirradiation metallography. 


\section{REFERENCES}

1. J. R. Engle, Planning Guide for HTGR Safety and Safety-Related Research and Development, ORNL-4968 (May 1974).

2. G. H. Llewellyn, ORNL, personal communication to S. H. Freid, Bechte1 Corporation.

3. H. R. W. Cobb, G. B. Engle, and S. J. S. Perry, Characterization of Production Grade H-327 Graphite for HTGR Design, GA-10389

(November 1970).

4. R. M. Carrol1, R. B. Perez, and O. Sisman, J. Am. Ceram. Soc. $\underline{48}$, 55 (1965).

5. T. B. Lindemer and M. D. Allen, J. Am. Ceram. Soc. 52, 233 (1969).

6. C. M. Blood and A. P. Malinauskas, Gas-Cooled Reactor Programs Annua1 Progress Report, Period Ending December 31, 1972, ORNL-4911 (March 1974).

7. C. M. Blood and A. P. Malinauskas, Nuclear Safety Program Annual Progress Report for Period Ending December 31, 1970, ORNL-4647 (May 1971). 
ORNL/TM-6399

Dist. Category UC-77

Interna1 Distribution

1. D. A. Costanzo

2. W. P. Eatherly

3. F. J. Homan

4-13. P. R. Kasten

14. T. B. Lindemer

15. E. L. Long, Jr.

16-25. A. P. Malinauskas

26. R. P. Wichner

27. D. P. Stevens

28. Laboratory Records - RC
29-30. Laboratory Records

31. Document Reference Library

32. Central Research Library

33. Patent office

34. E. L. Gaden (Consultant)

35. L. J. Colby (Consultant)

36. L. E. Swabb (Consultant)

37. K. D. Timmerhaus (Consultant)

38. G. R. Choppin (Consultant)

\section{External Distribution}

39. S. H. Freid, Bechtel Corporation, Norwalk, California

40. H. J. de Nordwa11, Commission of the European Communities, Avenue Francids Peters 31, Stocke1, B-1150 Brussels, Belgium

41. Office of Assistant Manager, Energy Research and Development, DOE-ORO

42. Director, Nuclear Research and Development Division, DOE-ORO

43-44. Director, Division of Nuclear Power Development, DOE Washington, D. C. 20545

45-221. Given distribution as shown in TID-4500 under Gas-Cooled Reactor Technology category 